\title{
Investigating the Hydrodynamics of High Temperature Fluidized Bed by
}

\section{Recurrence Plot}

\author{
Reza Zarghami ${ }^{1}$, Forough Sharifi, Navid Mostoufi \\ School of Chemical Engineering, College of Engineering, University of Tehran, P.O. Box 11155/4563, \\ Tehran, Iran
}

\begin{abstract}
Effect of temperature on the hydrodynamics of bubbling gas-solid fluidized beds was investigated using recurrence plot (RP) and recurrence quantification analysis (RQA) due to their capabilities for determining the whole bed complexity in a simple way. For this purpose, pressure fluctuations of a fluidized bed of sand particle were measured at various gas velocities and temperatures. Recurrence quantification analysis showed that by increasing the temperature up to $300{ }^{\circ} \mathrm{C}$, both determinism and laminarity increase due to formation of larger bubbles whereas entropy and recurrence rate decrease. To better detecting the different structures of in the bed recurrence plot at higher temperature, pressure fluctuations were also decomposed through wavelet transform. It was shown that at low gas velocity, the macro structures became dominate with increasing the bed temperature due to increase in the rate of bubble coalescence. The bubble diameter was estimated from the incoherent component of the cross power spectra of pressure signals at various temperatures and velocities. The incoherent results and standard deviation of measured pressure fluctuations confirmed that by increasing the bed temperature up to $300{ }^{\circ} \mathrm{C}$, bubbles grow up to a maximum diameter, after which they became smaller. In addition, the trend of the largest positive Lyapunov exponent was estimated through the

\footnotetext{
${ }^{1}$ Corresponding author. Tel.: +98 216696 7797; fax: +98 216646 1024. E-mail address: rzarghami@ut.ac.ir
} 
recurrence plot patterns. It was shown that a bubbling fluidized bed is a chaotic system at higher temperatures. It was found a maximum in the estimated largest positive Lyapunov exponent at $300{ }^{\circ} \mathrm{C}$ corresponds to the larger bubbles.

Keywords: High temperature fluidization, hydrodynamics, pressure fluctuations, recurrence plot, recurrence quantification analysis

\section{Introduction}

Many industrial fluidized beds, which are used in many processes such as combustion, gasification and fluid catalytic cracking, operate at high temperature [1-3]. Investigation of the hydrodynamics of fluidized beds through measurement of bed pressure is easy to perform. Some remarkable advantages of pressure signals are that they are easy to measure, have high accuracy, and are relatively inexpensive to obtain, do not alter the local hydrodynamic considerably and include the effect of many dynamic phenomena taking place in fluidized beds [4]. However, most of such measurements have been carried out at ambient temperatures.

Fan et al. [5] explored the major sources of pressure fluctuations in a fluidized bed. They indicated that the origin of pressure fluctuations lies in phenomena such as coalescence, motion and formation of bubbles as well as jet flow of the gas. Hartman and Trnka [6] analyzed pressure fluctuations in the frequency domain by fast Fourier transform. They showed that this method is able to recognize alterations in the hydrodynamic state of the bed caused by minor changes in the bed mass and size of particles. Using the wavelet transform, Guo et al. [7] decomposed pressure signals into approximation and details at different resolutions and showed that the number of 
peaks in the sixth detail signal represents the number of bubbles passing through the pressure probe measurement region over the sampling time. In the recent years, new analytical techniques of fuzzy c-means clustering [8] and least square support vector machine [9-10] also have been proposed to study the complex dynamics of gas-solid systems.

So far, a few experimental studies have been reported on hydrodynamics of fluidized beds at high temperatures. The majority of these investigations, however, were focused on the effect of temperature on minimum fluidization velocity and regime transition from bubbling to turbulent [11-14]. Correlations offered by Kunii and Levenspiel [2] and Formisani et al. [15] for predicting bubble size and minimum fluidization velocity predict an increase in the bubble size and a decrease in the minimum fluidization velocity by increasing the bed temperature. Hatate et al. [16] used Geldart B particles in their investigation and reported that the bubbles size increases by increasing the bed temperature from ambient to $327^{\circ} \mathrm{C}$. Sanaei et al. [17] reported that solids mixing and diffusivity of Geldart B particles increase by increasing temperature up to $300{ }^{\circ} \mathrm{C}$ and decrease at higher temperatures. They concluded that the bubbles size increases by increasing the bed temperature up to $300{ }^{\circ} \mathrm{C}$ and bubbles become smaller at higher temperatures. Nemati et al. [18] investigated the hydrodynamics of fluidized bed through analysis of pressure fluctuations in time and frequency domains. They used sand particles (Geldart B) in their experiments at various temperatures, ranging from ambient to $400{ }^{\circ} \mathrm{C}$. They concluded that increasing the temperature up to $300{ }^{\circ} \mathrm{C}$ causes the bubbles to grow in size and reach their maximum size at $300{ }^{\circ} \mathrm{C}$. Also, they showed that the drag force acting on the emulsion phase reaches a minimum at this temperature. Hagh-Shenas-Lari and Mostoufi [19] evaluated probabilities of fluidization regimes at various gas velocities and temperatures. They showed that 
the velocity of transition from bubbling to turbulent regime increases by increasing the bed temperature.

Hydrodynamics of fluidized bed is intrinsically non-linear. While only time and frequency domain analyses of dynamical variables of the fluidized bed at higher temperature are not capable of determining the whole complexity of the fluidized bed system, the study of nonlinear behavior of fluidization at higher temperature still is a relatively new subject. Therefore, nonlinear methods of analysis have been utilized by many researchers for investigating this phenomenon [20]. All these methods are based on reconstruction of an attractor. However, they are associated with restrictions such as uncertainty in the reconstruction through experimental data. Parameters for the state space reconstruction were estimated by Zarghami et al. [21]. They stated that the value of these parameters may differ based on the technique applied for this purpose. In addition, when the dimension of the attractor is more than three, it cannot be visualized [22-23]. Conventional nonlinear analysis of a measured time series in a fluidized bed in the state space is not straightforward and still needs more research. In addition, Zarghami et al. [21] showed that there is a kind of uncertainty in reconstruction of attractor of fluidized bed from its pressure fluctuations. On the other hand, analysis of pressure fluctuations in the state space typically requires long term data sampling that leads to problems such as large capacity for data storage and long time required for data processing [24-25]. All these limitations have encouraged researchers to search for new techniques which can overcome these limitations.

Recurrence plot (RP) is a powerful tool that can solve some of the problems described above. This technique eliminates the necessity of long-term data sampling, does not need time series 
embedding, avoids time consuming algorithm and also enables analysis of non-stationary, short term and chaotic time series [26]. Moreover, using RP, any $m$-dimensional phase space trajectory can be represented visually in a two-dimensional space [26-27]. Furthermore, while embedding is required for reconstruction of an attractor in the state space, the RP may be constructed without embedding. In fact, all information contained in the embedded RP can be attained in the non-embedded one. Few researchers have used this technique to analyze pressure fluctuations of a fluidized bed. Wang et al. [28] used RP and recurrence quantification analysis (RQA) to analyze pressure fluctuations and recognize flow regimes through RQA parameters. Babaie et al. [27] employed the RP technique to analyze the hydrodynamics of gas-solid fluidized beds and were able to detect different hydrodynamic structures of the system (i.e., macro, meso and micro). Sedighikamal and Zarghami [29] used the RP and proposed a new technique for prediction of transition velocity from bubbling to turbulent fluidization regime. Babaie et al. [30] presented a new technique for on-line monitoring of fluidized bed hydrodynamics. They showed that determinism is sensitive to small changes in the particles size while is not sensitive to slight variations in the gas velocity. A combination of wavelet analysis and RQA methods was also used to characterize different structures in a fluidized bed [31-32].

In all above mentioned investigations, RP and RQA were applied to the data obtained at ambient temperature while industrial fluidized beds operate at high temperature. Hence, there is a need for investigating the hydrodynamics of fluidized beds at high temperature through RP and RQA. To address this issue, experiments were carried out in a fluidized bed up to $400{ }^{\circ} \mathrm{C}$ in the present work. While the RP is a qualitative representation of the hydrodynamic status of the fluidized bed, the RQA was introduced in this work to quantify the patterns in RPs of pressure fluctuations 
of fluidized bed. Recurrence rate $(R R)$, determinism (DET), laminarity (LAM), entropy (ENT), Lyapunov exponent, as RQA parameters, were employed to investigate the nonlinearity of the complex dynamics of a fluidized bed at high temperatures in a simple way. This method can be used for on-line monitoring of hydrodynamic status of fluidized beds. Moreover, two more quantitative measures, i.e., coherence of pressure time series and wavelet transform, were used to further characterize the bed hydrodynamics of fluidized beds at elevated temperatures.

\section{Theory}

\subsection{Recurrence plot}

$\mathrm{RP}$ is a two dimensional graph of an $N \times N$ matrix (where $N$ is the number of points on the phase space trajectory) which makes it possible to visualize a high directional attractor in a state space [33]. The recurrence matrix is defined as:

$$
R_{i, j}=\Theta\left(\varepsilon-\left\|x_{i}-x_{j}\right\|\right)
$$

where $x_{i}$ and $x_{j}$ are points in the phase space trajectory at which the system is situated at times $i$ and $j, \varepsilon$ is a predefined threshold ( 0.1 in this work), $\Theta(\cdot)$ is the Heaviside function and $R_{i, j}$ denotes the elements of the recurrence matrix. This matrix compares the states of the system at times $i$ and $j$. If the states of the system at theses time are similar, i.e., $x_{i}$ and $x_{j}$ are closer than $\varepsilon$, $R_{i, j}=1$, otherwise, $R_{i, j}=0$. Whenever the distance between two points is shorter than the radius threshold $\varepsilon$, these points are considered as recurrence points and are shown with black dots, otherwise, are shown by white dots on the RP. Therefore, while high-dimensional attractors in a state space are very difficult to visualize, any state space attractor can be represented in a 2D plot by the RP. 
Generally, the graphical structures in a RP consist of three distinct components: single dots, horizontal/vertical lines and diagonal lines. These structures reflect the dynamics of the system [26, 34]. Single dots on a RP correspond to uncorrelated random behavior of the system [26] and represent states which occur rarely in a fluidized bed [27-30]. In a fluidized bed, single dots correspond to particle-particle interactions as well as noise effects [27]. RPs are symmetric with respect to their main diagonal lines, thus, both horizontal and vertical lines are dynamically equal [26]. Horizontal/vertical lines identify the times in which a specific dynamic behavior remains constant or changes slowly. These lines in a fluidized bed correspond to movement of meso structures, such as clusters and small bubbles [31-32]. Diagonal lines in a RP correspond to the states which are similar at different epochs and can be seen in deterministic processes [26]. In a fluidized bed, long diagonal lines can be attributed to deterministic phenomena in the bed [27, 31-32]. These phenomena in a fluidized bed are macro structure phenomena s, uch as bubble coalescence, movement of large bubbles and bubble eruption [27, 31-32].

\subsection{Recurrence quantification analysis}

To have a qualitative understanding of the RP, Webber and Zbilut [34] introduced the RQA and further enriched by the introduction of other variables. Marwan et al. [26] extended the RQA to parameters that describe various structures in the RP, such as single dots, diagonal and vertical (or horizontal) lines. The RQA even can be used for analysis non-stationary time series and this is one of the most remarkable features of this method. In the followings, some RQA parameters are described.

\section{Recurrence rate}


The recurrence rate $(R R)$ represents density of recurrence points (black dots) in a RP.

$R R=\frac{1}{N^{2}} \sum_{i, j=1}^{N} R_{i, j}$

It is evident that recurrence rate increases with increasing the radius threshold. Therefore, recurrence rate is generally used to determine the value of radius threshold [26]. This parameter quantifies the fraction of recurrence states in the system [26].

\section{Determinism}

Determinism (DET) measures the proportion of recurrence points forming diagonal lines in the RP [26]:

$D E T=\frac{\sum_{l=l_{\min }}^{N} l P(l)}{\sum_{l=1}^{N} l P(l)}$

where $P(l)$ is the probability of the length of diagonal lines with length $l$. A minimum length should be considered for diagonal lines $\left(l_{\min }\right)$ and shorter diagonal lines are not considered in the calculation of determinism. Usually, the minimum length of lines is considered to be consisted of two points [35]. Periodic systems have long diagonal lines, chaotic systems have very short diagonal lines and stochastic systems have no diagonal lines unless the radius threshold is selected too large. The determinism measures the predictability of the system and is small for a stochastic system while is large for a periodic system [26].

\section{Laminarity}

Laminarity $(L A M)$ is similar to determinism with the difference that instead of diagonal lines, horizontal/vertical lines are considered [26]: 
$L A M=\frac{\sum_{v=v_{\min }}^{N} v \cdot P(v)}{\sum_{v=1}^{N} v \cdot P(v)}$

where, $P(v)$ is the probability of finding vertical lines with length $v$ in the RP and $v_{\min }$ is the minimum length of these line which is usually is considered to be two points [26, 31]. A large laminarity indicates more persistency of the system behavior which means that the system insists on a special behavior in different periods. The laminarity is the probability of states which do not change or change very slowly, called laminar states [26].

\section{Entropy}

The Shannon entropy (ENT) indicates the probability distribution of the diagonal lines with length $l[26]$ :

$$
E N T=-\sum_{l=l_{\min }}^{N} P(l) \log _{2} P(l)
$$

In fact, this entropy reflects the complexity of the system. For example, for a periodic system, diagonal lines in the RP have similar distribution which results in entropy close to zero while for a stochastic system the entropy assumes a greater value. In fact, the entropy is a measure of how much information is needed for reconstructing the system [29, 35].

\subsection{Coherence of pressure time series}

In the recent years, frequency domain analysis has been proposed to study the complex dynamics of a fluidization system. The power spectral density function (PSDF) of pressure fluctuations, which express the behavior of a time series in the frequency domain, can be decomposed into components corresponding to different phenomena occurring in a fluidized bed. van der Schaaf 
et al. [36] proposed a decoupling method based on decomposition of the PSD into a coherentoutput power spectral density (COP) and an incoherent-output power spectral density (IOP) as:

$$
\begin{aligned}
& C O P=\gamma_{x y}^{2}(f) \Phi_{y y}(f) \\
& I O P=\left(1-\gamma_{x y}^{2}(f)\right) \Phi_{y y}(f)
\end{aligned}
$$

where $\gamma_{x y}{ }^{2}$ is coherence between two time series $x$ and $y$ in frequency domain and is defined as [36]:

$\gamma_{x y}^{2}(f)=\frac{\Phi_{x y}(f) \Phi_{x y}^{*}(f)}{\Phi_{x x}(f) \Phi_{y y}(f)}$

and $\Phi_{x y}$ is the cross power spectral density of two individual signals $x$ and $y . \Phi_{x x}$ and $\Phi_{y y}$ are the power spectral density of signals $x$ and $y$, respectively. The coherence between two pressure time series from a fluidized bed in positions $x$ and $y$ can be used to identify effects of different phenomena in the pressure fluctuations. In the present work, $x$ is the pressure fluctuations in the plenum, or slightly above it, and $y$ stands for the pressure fluctuations at a position within the bed. van der Schaaf et al. [36] showed that the incoherent component corresponds to the local fluctuations induced by bubble motions or local turbulence, and its standard deviation can be used to estimate the bubble size in a freely bubbling fluidized bed as follows:

$D_{b} \approx \frac{\sigma_{x y}}{\rho_{S} g\left(1-\varepsilon_{m f}\right)}$

where $\sigma_{x y}$ is the standard deviation of incoherent pressure time series, $\varepsilon_{m f}$ is the bed porosity at incipient of fluidization and $\rho_{s}$ is the particle density. van der Schaaf et al. [36] showed that the mean bubble diameters calculated by this equation are in good agreement with the bubble sizes predicted by the semi-empirical equation of Darton et al. [37]. Later, van Willigen et al. [38] compared the mean bubble diameter determined by pressure fluctuations analysis with that 
obtained from video imaging and obtained from the correlation of Darton et al. [37]. They concluded that the bubble diameter calculated from the incoherent standard deviation agrees well with that determined by video imaging and Darton et al. [37] correlation.

\subsection{Wavelet transform}

Wavelet transform plays an important role in the investigation of self-similar signals and systems. This technique can provide information about signals in time and frequency domain, simultaneously. The wavelet transform of a continuous signal is defined as [39]:

$\psi_{j k}(t)=\frac{1}{\sqrt{|j|}} \sum_{i=1}^{N} \psi\left(\frac{t-k}{j}\right)$

where $\psi$ is mother wavelet function, $j$ and $k$ represent wavelet decomposed information level and time lag coefficient, respectively. Based on the wavelet transform, the original signal can be decomposed into multi-resolution signals with different frequency bands. In fact, the raw data can be decomposed into different approximation and detail signals. The original signal may be reconstructed from the information contained in the last approximation signal and detail signals. There are different types of mother wavelets, such as Haar, Daubechies, Morlet and Symlet. In the present study, the second-order Daubechies wavelet was used for analyzing high temperature pressure fluctuations.

\subsection{Lyapunov exponent}

Chaotic systems, such as fluidized beds, are sensitive to initial conditions [40]. Thus, it can be expected that any two initial points in such systems would grow apart exponentially in time. The Lyapunov exponent measures such divergence (or convergence) in a dynamical system [41]. The Lyapunov exponent is a measure for identifying whether or not a system is chaotic. This 
parameter is determined based on the divergence of nearby trajectories. For a dynamical system, sensitivity to the initial condition is quantified by the Lyapunov exponent. For a better understanding, consider two trajectories with nearby initial conditions. If $d_{0}$ is a measure of initial distance between two starting points, at a small but later time the distance is [41]:

$d(t)=d_{0} e^{\lambda t}$

where $\lambda$ is the Lyapunov exponent. It is well established that a system is chaotic if its average Lyapunov exponent is a positive number. If the Lyapunov exponent is negative, slightly separated trajectories converge and the evolution is not chaotic [41]. Eckmann et al. [33] found that the inverse of the longest diagonal line in the RP (except the main diagonal) is proportional to the largest Lyapunov exponent of the system.

\section{Experiments}

The high temperature fluidized bed set-up used in this study is schematically shown in Figure 1. The column was made of stainless steel with an inner diameter of $0.11 \mathrm{~m}$ and height of $2 \mathrm{~m}$. The distributor was a porous plate made of Inconel 600 (Mott Metallurgical Corporation) with a porosity of $10 \mu \mathrm{m}$. The air was supplied by a compressor and its flow rate was controlled by a mass flow controller (Alicat). Solid particles entrained by the air flow were separated from the air by a cyclone at the top of the column and returned back to the bed. Sand particle with an average size of $420 \mu \mathrm{m}$ and density of $2640 \mathrm{~kg} / \mathrm{m}^{3}$ were used in all experiments. The minimum fluidization velocity for these particles at ambient temperature was measured to be $0.182 \mathrm{~ms}^{-1}$. Other properties of these particles are given in Table 1. Particle size distribution was obtained by screening and the average diameter of particles was evaluated from: 


$$
\overline{d_{p}}=\frac{1}{\sum_{i}\left(\frac{m_{i}}{d_{p i}}\right)}
$$

where $m_{i}$ is the mass fraction of particles of size $d_{p i}$.

A JUMO thermocouple with a measurement accuracy of $2.5^{\circ} \mathrm{C}$ was inserted to the bed at $5 \mathrm{~cm}$ above the distributor. A PID controller (Autonics Co.) was used to keep the bed temperature at the desired value in each test. In order to prevent heat losses, the column was covered with rock wool. A piezo-resistive pressure transducer (Kistler 7261) was used to measure pressure fluctuations at $5 \mathrm{~cm}$ above the distributor. This probe position is appropriate for monitoring the dynamic state of the entire bed [42]. Operational temperature range of the pressure transducer was -40 to $240{ }^{\circ} \mathrm{C}$ and temperature coefficient of sensitivity for this sensor was $-0.02 \% /{ }^{\circ} \mathrm{C}$. Since the temperature in the bed was as high as $400{ }^{\circ} \mathrm{C}$, a stainless steel cylindrical jacket was installed around the pressure probe to prevent sensor from heating by flow of water. In order to avoid blockage of the sensor by sand particles, a stainless steel screen was put at the end of its probe.

The measured signals were band-pass filtered (hardware) at lower cut-off frequency of $0.1 \mathrm{~Hz}$ to remove the bias value of the pressure fluctuations and upper cut-off Nyquist frequency $(200 \mathrm{~Hz})$. The filtered signals then were de-noised through wavelet de-noising method to remove probable thermal noise of the pressure fluctuations. The pressure transducer was connected to a 16 bit data acquisition board (Advantech 1712L). The frequency of sampling of pressure fluctuations was $400 \mathrm{~Hz}$, satisfying the Nyquist criterion. This sampling frequency is also in accordance with the criterion of 50-100 times the average cycle frequency (typically between 100 and $600 \mathrm{~Hz}$ ) which is required for nonlinear evaluation of pressure fluctuations in bubbling fluidized beds [24]. 
Experiments were carried out in the range of temperature from 30 to $400{ }^{\circ} \mathrm{C}$ and in a range of gas velocity between 0.1 and $0.9 \mathrm{~m} / \mathrm{s}$ (based on ambient temperature). Actual gas velocities were calculated by taking into account the actual air density at the operating temperature.

Experimental procedure in each test was as follows:

Step 1: Keeping the controller set points at desired temperature,

Step 2: Increasing the gas velocity slightly (starting from minimum fluidization velocity),

Step 3: Waiting for the controller to take the bed back to the desired temperature,

Step 4: Recording pressure fluctuations at each velocity,

Step 5: Repeating above step for new desired temperature.

\section{Results and discussion}

Standard deviation is a simple method for analyzing pressure fluctuation signals. This parameter has been generally used to determine the transition from bubbling to turbulent fluidization. Figure 2 shows the standard deviation of pressure fluctuations versus superficial gas velocity for sand particles at various bed temperatures. It can be seen in this figure that the standard deviation initially increases, then decreases by increasing the gas velocity. The velocity at which the standard deviation reaches its maximum is the onset of turbulent fluidization, $U_{c}$. Based on Eq. (9), bubble diameter is directly proportional to the standard deviation of pressure fluctuations. Bubble diameters at various gas velocities and temperatures were estimated from Eq. (9) and shown in Figure 3. As can be seen in this figure, the trend of variation in the bubble diameter with superficial gas velocity is the same as the standard deviation. By increasing the temperature up to $300{ }^{\circ} \mathrm{C}$, bubbles become larger with increasing the gas velocity and further increasing the bed temperature results in formation of smaller bubble. 
It has been shown by many researchers that increasing the standard deviation of pressure fluctuations can be related to the increase in the bubble size [43-45]. Pressure fluctuations of a fluidized bed have been widely studied in literature and origin, propagation and attenuation of pressure waves in gas-solid fluidized beds were highlighted in many researches (e.g. [46]). There is no single source for pressure fluctuations. These fluctuations originate from a number of phenomena within the bed which happen at the same time, including bubble coalescence and splitting. However, higher rate of bubbles coalescence in the bubbling regime of fluidization (compare to their splitting) results in formation of larger bubbles and consequently greater standard deviation of pressure fluctuations. Therefore, it can be concluded that by increasing temperature up to $300{ }^{\circ} \mathrm{C}$, the coalescence of bubbles is more significant compared to their splitting which leads to formation of larger bubbles. At higher bed temperatures, the bubble size follows a reverse trend.

Variation of $U_{c}$ versus temperature is illustrated in Figure 4 for the operating conditions considered in this work. Also, $U_{c}$ values obtained by Hagh-Shenas-Lari and Mostoufi [19] and those predicted by the correlation of $\mathrm{Bi}$ and Grace [47] are also shown in this figure. It can be seen in this figure that all the curves present a similar trend which demonstrates which is the delay of transition from bubbling to turbulent by increasing the bed temperature. It is worth mentioning that the correlation of $\mathrm{Bi}$ and Grace [47] was developed based on experimental data at room temperature and, as shown in Figure 4, it is not accurate for higher temperatures. HaghShenas-Lari and Mostoufi [19] employed a different methodology for obtaining the transition velocity from bubbling to turbulent fluidization which is the reason for reporting different values 
compared with this work. However, they explained such delay in occurrence of $U_{c}$ at higher temperature with the lower gas density and higher gas viscosity at higher temperatures.

\subsection{Effect of gas velocity on $R P$}

Figures 5a-h demonstrate recurrence plots of pressure fluctuations of the fluidized bed at various superficial gas velocities operating at $300{ }^{\circ} \mathrm{C}$. It can be seen that the patterns of structures within the RP change with increasing the gas velocity. Different kinds of structures can be seen in the RP, including local white area (LWA) and local bold area (LBA). As mentioned by Babaie et al. [27], LWA and LBA correspond to macro and finer (meso and micro) structures, respectively. Changes in these areas with the gas velocity represent changes in the hydrodynamics of the bed and variations in macro, meso and micro structures. It should be noted that the amplitude of pressure fluctuations increases with increasing the gas velocity. Pressure data points with larger amplitudes have a distance larger than the radius threshold and are not considered as recurrence points. These points make LWAs. Therefore, increasing the gas velocity from $0.38 \mathrm{~m} / \mathrm{s}$ to 0.76 $\mathrm{m} / \mathrm{s}$ leads to a wider LWA, this is due to higher amplitude of pressure fluctuations generated by larger bubbles. Cai et al. [48] showed that in the bubbling regime, the rate of bubble coalescence is dominant and bubbles increase in size with increasing the gas velocity, which is the reason for observing higher pressure amplitudes in a bubbling fluidized bed when increasing the gas velocity. By further increasing the gas velocity from $0.95 \mathrm{~m} / \mathrm{s}$ to $1.32 \mathrm{~m} / \mathrm{s}$, the size of LWAs remain unchanged, indicating that macro structures (large bubbles) do not change remarkably. These is also consistent with reports of Chen and $\mathrm{Bi}$ [44] who found that bubbles grow in size due to coalescence at low gas velocities, reach to their maximum stable size and remain at this size at higher velocities, while their separation distance decreases with increasing the superficial 
gas velocity. This trend suggests that the hydrodynamics of fluidized bed is not affected by finer structures in this range. Sudden growth of LBAs from $1.51 \mathrm{~m} / \mathrm{s}$ to $1.70 \mathrm{~m} / \mathrm{s}$ can be attributed to transition of the flow regime from bubbling to turbulent (see Figure 4). This sudden growth of LBAs is due to reduction in the size of bubbles at the onset of turbulent regime of fluidization where bubble splitting becomes dominant. This is also in agreement with the works of Chen and Bi [44], Cai et al. [48] and Bi et al. [49] who showed that bubble splitting becomes dominant in the turbulent regime and number of bubbles increases with increasing the gas velocity in this regime. Trend of changes of LBAs against the superficial gas velocity is different from that of LWAs. At first, by increasing the gas velocity from $0.38 \mathrm{~m} / \mathrm{s}$ to $0.76 \mathrm{~m} / \mathrm{s}$, LBAs shrink due to presence of larger bubbles. The size of LBAs remains constant until the superficial gas velocity reaches $1.32 \mathrm{~m} / \mathrm{s}$, indicating that macro structures (large bubbles) remain approximately constant. Finally, the LBAs increase when the superficial gas velocity increases up to $1.51 \mathrm{~m} / \mathrm{s}$. In fact, at superficial gas velocities greater than $U_{c}$, the amplitude of pressure fluctuations decreases because of bubble splitting. Accordingly, number of pressure fluctuations with a distance shorter than the radius threshold increases and they are considered as recurrence points. Therefore, increasing the gas velocity at the onset of turbulence regime causes a sudden growth of LBAs.

\subsection{Effect of gas velocity on RQA parameters}

Figures 6a-d show variation of determinism, laminarity, recurrence rate and entropy at various superficial gas velocities. These figures suggest that changes in RQA parameters against gas velocity can be divided into three regions. At low gas velocities, changes of these parameters are steeper which can be explained by fast formation and growth of bubbles. This indicates that in this region, macro structures (large bubbles) start to become dominant due to coalescence of 
bubbles, thus, pressure fluctuations become more periodic. As a result, determinism and predictability of the system increases and entropy decreases when the gas velocity is increased at low gas velocities. In this region, the LBAs shrink because of bubble coalescence and consequently, the recurrence rate decreases. Greater amplitude of pressure fluctuations in this region leads to increase in the laminarity. In other words, by increasing the superficial gas velocity, the laminar states of the system increase, which means that the system insists on its previous behavior. This corresponds to growth of macro structures, causing more persistence in the system.

The second region in Figures 6a-d is where there is no considerable change in the RQA parameters when the gas velocity changes. This can be attributed to the balance between bubble splitting and coalescence and growth of finer structures (meso and micro structures such as: clusters, small bubbles and interaction among particles) in the bed as a result of increasing the gas velocity. At higher gas velocities, the slope of changes of RQA parameters against the gas velocity changes in the opposite to that at low gas velocities. This alteration suggests that the regime is transferred from bubbling to turbulent. In this region, the size of bubbles decreases because bubble splitting overtakes bubble coalescence in turbulent regime. This leads to smaller determinism at greater entropy. Also, the amplitude of pressure fluctuations decreases in this region which results in increasing the recurrence rate.

\subsection{Effect of temperature on $R P$}

The wavelet transform was applied to pressure fluctuations for better detecting different structures in the fluidized bed. An appropriate mother wavelet should be selected in order to 
decompose the signals into high and low frequencies. The best choice of the mother wavelet is the one that results in the minimum difference between reconstructed (from decomposed subsignals) and original signals. Based on this concept, Daubechies 2 was selected in this work as the mother wavelet. Using this mother wavelet, a signal was decomposed into several levels. Each level of decomposition contains information associated with its scale. In this study, pressure fluctuations were decomposed into 8 levels. In fact, the appropriate level of decomposition is the one at which the Shanon entropy becomes close to zero [31].

Figure 7 shows determinism of pressure fluctuations at various temperatures and different decomposition levels. As can be seen in this figure, with increasing the fraction of macro structures (movement of large bubbles and bubble eruption in the bed), the determinism becomes greater which indicates the periodic behavior of the system. It can be concluded from Figure 7 that macro structures of very low frequencies can be represented by levels 7 and 8 of the decomposed signal. Meso structures of higher frequencies (small bubbles and clusters) are described by levels 3 to 6 of detail signals. Micro structures have the minimum fraction of determinism. This indicates that finer structures (interaction among particles, small bubble and clusters as well as noise effects) have the least periodic behavior and the most stochastic behavior. Therefore, micro structures of very high frequency are described by 1 and 2 of detail signals.

$\mathrm{RP}$ of the main signal as well as RPs of macro, meso and micro structures for sand particles at $300{ }^{\circ} \mathrm{C}$ and gas velocity of $0.95 \mathrm{~m} / \mathrm{s}$ are illustrated in Figure 8 . It can be seen in this figure that the RP of macro structures is more similar to the main signal. Also, LWAs and LBAs are clearer 
in the RP of macro structures. RPs of macro structures at various temperatures are illustrated in Figures 9a-c. As can be seen in these figures, with increasing the temperature up to $300{ }^{\circ} \mathrm{C}$, LWAs become larger and LBAs increase at higher temperatures. As described previously, LWAs arise from high amplitude pressure fluctuations generated by larger bubbles. Therefore, it can be concluded that bubbles grow up to a maximum size by increasing the temperature up to $300{ }^{\circ} \mathrm{C}$, after which the bubbles become smaller. This trend is evaluated quantitatively through RQA parameters in the next section.

\subsection{Effect of temperature on RQA parameters}

Figures $10 \mathrm{a}-\mathrm{d}$ show RQA parameters at various temperatures, ranging from $30{ }^{\circ} \mathrm{C}$ to $400{ }^{\circ} \mathrm{C}$. It is observed in Figure 10a-c that by increasing the temperature up to $300{ }^{\circ} \mathrm{C}$, both determinism and laminarity increase whereas entropy and recurrence rate decrease. A greater value of determinism reflects a more predictable and deterministic behavior of the system. Thus, the above mentioned trend suggests that by increasing the temperature up to $300{ }^{\circ} \mathrm{C}$, larger bubbles are formed and their passing through the bed results in more predictable and deterministic behavior of the bed. This trend also suggests that there is a maximum periodic state at $300{ }^{\circ} \mathrm{C}$ at which the entropy is minimum (Figure 10c). This can be explained by considering the maximum size of bubbles at this temperature. Figure 10c also shows that laminarity increases by increasing the temperature up to $300{ }^{\circ} \mathrm{C}$. In this case, laminar phases of the system increase, i.e., the system insists on its previous behavior. This corresponds to existence of bubbles at their maximum stable sizes within the bed which cause more persistence in the system. 
Figure 10d illustrates that the recurrence rate decreases by increasing the temperature up to 300 ${ }^{\circ} \mathrm{C}$ and then acts oppositely. This trend can be explained by the fact that size of bubbles, as discussed before, increases up to $300{ }^{\circ} \mathrm{C}$ and generate larger amplitude of pressure fluctuations, which results in decreasing the number of recurrence points. However, by further increasing the temperature beyond $300{ }^{\circ} \mathrm{C}$, bubbles become smaller and the amplitude of pressure fluctuations decrease which leads to increase in the recurrence rate.

\subsection{Lyapunov exponent}

As expressed by Eckmann et al. [33], one of the easiest and the most straightforward methods of calculating the Lyapunov exponent is the use of recurrence quantification analysis. According to this method, the inverse of the longest diagonal line in a RP is proportional to the Lyapunov exponent of the system. The longest diagonal line of RP is easily to achieve based on Eq. (3). For this purpose, length of the line considered for evaluating the determinism is changed from zero to a positive value which represents the longest diagonal line. The Lyapunov exponent is a parameter by which it can be recognized whether a system is chaotic or not. In other words, if the largest Lyapunov exponent is positive, the bubbling fluidized bed is a chotic system. Figure 11 illustrates the Lyapunov exponent versus temperature at superficial gas velocity of $0.6 \mathrm{~m} / \mathrm{s}$ and $L / D=1.5$. According to this figure, the fluidized bed possesses a positive value of Lyapunov exponent in a wide range of high temperature indicating the chaotic nature of fluidized bed behavior. In addition, it was shown that the estimated positive of Lyapunov exponent increases by increasing the temperature up to $300{ }^{\circ} \mathrm{C}$, however by further increasing the temperature beyond $300{ }^{\circ} \mathrm{C}$, this estimated value decreases. 


\section{Conclusion}

Recurrence plot and recurrence quantification analysis were used to study the hydrodynamics of fluidized bed at high temperatures. Recurrence rate, determinism, laminarity and entropy, as RQA parameters, were employed to study nonlinearity of the complex dynamics in fluidized bed at high temperature in a simple way. Moreover, the wavelet transform was also applied to pressure fluctuations for better detecting different structures in the fluidized bed.

By plotting these RQA parameters against the gas velocity at a specified temperature and considering wavelet decomposition technique, three different hydrodynamic regions were observed. At low gas velocities the slop is high. In this region, macro structures are dominant because the bubbles coalescence overtakes bubble splitting. At intermediate velocities there was no considerable change in the RQA parameters because rates of bubble coalescence and splitting are of the same order. By further increasing the gas velocity, the slope again changes, but in opposite to that at low velocities. This trend indicates that the fluidization regime has changed from bubbling to turbulent. Effect of temperature on RQA parameters was also investigated. It was found that by increasing the bed temperature up to $300{ }^{\circ} \mathrm{C}$, determinism and laminarity increase and entropy and recurrence rate decrease, after which they follow an opposite trend. It was concluded that bubble grow up to a maximum size at $300{ }^{\circ} \mathrm{C}$. The recurrence plot technique eliminates the necessity of long-term data sampling (which cause many difficulties in online hydrodynamic monitoring), time series embedding (which is required for any conventional chaos analysis method for reconstruction of attractor) and time consuming algorithm. Therefore, this method can be used in on-line monitoring of fluidized bed hydrodynamics. 
A coherence method, based on decoupling of pressure fluctuations recorded simultaneously in two points of the bed, was used to estimate the bubble diameter. It was shown that bubbles grow in size with increasing the bed temperature up to $300{ }^{\circ} \mathrm{C}$, and afterwards indicated a reverse trend.

Moreover, the largest positive Lyapunov exponent was estimated using the determinism equation. It was demonstrated that high temperature fluidized bed has chaotic behavior. The largest positive Lyapunov exponent increases by increasing the bed temperature up to $300{ }^{\circ} \mathrm{C}$, and then decreases.

\section{Acknowledgement}

The work was supported by Iranian National Science Foundation (Grant: Nonlinear Dynamics in Multiphase Systems).

\section{Nomenclature}

$\begin{array}{ll}d_{0} & \text { initial distance between trajectories } \\ d & \text { distance between trajectories } \\ d_{p i} & \text { particle diameter }(\mu \mathrm{m}) \\ \overline{d_{p}} & \text { mean particle diameter }(\mu \mathrm{m}) \\ D_{b} & \text { bubble diameter }(\mathrm{m}) \\ D E T & \text { determinism } \\ E N T & \text { entropy } \\ f & \text { frequency }(\mathrm{Hz})\end{array}$




\begin{tabular}{|c|c|}
\hline$j$ & wavelet decomposed information level \\
\hline$k$ & wavelet decomposed time lag coefficient \\
\hline$L A M$ & laminarity \\
\hline$L / D$ & aspect ratio \\
\hline$l$ & length of diagonal lines \\
\hline$v$ & length of vertical lines \\
\hline$l_{\min }$ & minimum length of diagonal lines \\
\hline$v_{\min }$ & minimum length of vertical lines \\
\hline$N$ & number of time series points \\
\hline$m_{i}$ & mass fraction of particles of size $d_{p i}$ \\
\hline$P_{x}(t)$ & pressure time series $(\mathrm{Pa})$ \\
\hline$P(l)$ & probability of the length $l$ of the diagonal lines \\
\hline$P(v)$ & probability of the length $v$ of vertical lines \\
\hline$P S D F$ & power spectral density function $\left(\mathrm{Pa}^{2} / \mathrm{Hz}\right)$ \\
\hline$R P$ & recurrence plot \\
\hline$R Q A$ & recurrence quantification analysis \\
\hline$R R$ & recurrence rate \\
\hline$R_{i, j}$ & recurrence plot matrix \\
\hline$t$ & time $(\mathrm{s})$ \\
\hline$U_{m f}$ & minimum fluidization velocity $(\mathrm{m} / \mathrm{s})$ \\
\hline$U$ & superficial gas velocity $(\mathrm{m} / \mathrm{s})$ \\
\hline$x_{i}$ & time series \\
\hline$x_{j}$ & time series \\
\hline
\end{tabular}

\section{Greek symbols}




$\begin{array}{ll}\sigma_{x y} & \text { standard deviation of incoherent pressure time series } \\ \gamma_{x y} & \text { coherence } \\ \varepsilon & \text { radius threshold } \\ \Theta & \text { Heaviside function } \\ \lambda & \text { Lyapunov exponent } \\ \rho_{\mathrm{s}} & \text { density of particles }\left(\mathrm{kg} / \mathrm{m}^{3}\right) \\ \Phi_{x y} & \text { cross power spectral density of signals } x \text { and } y\left(\mathrm{~Pa}^{2} / \mathrm{Hz}\right) \\ \Phi_{x x} & \text { power spectral density of signal } x\left(\mathrm{~Pa}^{2} / \mathrm{Hz}\right) \\ \psi & \text { mother wavelet function }\end{array}$

\section{References}

[1] D. C. Sau, S. Mohantyc, K. C. Biswal, Minimum fluidization velocity at elevated temperature in tapered fluidized bed, Chem. Eng. Process. 47 (2008) 2391-2394.

[2] D. Kunii and O. Levenspiel, Fluidization Engineering, 2nd ed., Butterworth-Heinemann, Boston, 1991.

[3] Q. J. Guo, G. X. Yue, J. Werther, Dynamics of Pressure Fluctuation in a Bubbling Fluidized Bed at High Temperature, Ind. Eng. Chem. Res. 41 (2002) 3482-3488.

[4] J. R. van Ommen, S. Srdjan, J. van der Schaaf, S. Gheorghiu, F. Johnsson, M. Coppens, Time-series analysis of pressure fluctuations in gas-solid fluidized beds - A review, Int. J. Multiphase Flow 37 (2011) 403-428.

[5] L. T. Fan, T. C. Ho, S. Hiraoka, W. P. Walawender, Pressure fluctuations in a fluidized bed, AIChE J. 27 (1981) 388-396.

[6] M. Hartman and O. Trnka, Physical characteristics of fluidized beds via pressure fluctuation analysis, AIChE J. 54 (2008) 1761-1769. 
[7] Q. J. Guo, G. X. Yue, S. Toshiyuki, S. Junichi, Flow characteristics in a bubbling fluidized bed at elevated temperature, Chem. Eng. Process. 42 (2003) 439-447.

[8] C. H. Wang, Z. P. Zhong, R. Li, J. Q. E, Intelligent fitting of minimum spout-fluidised velocity in spout-fluidised bed, Canadian Journal of Chemical Engineering, 89(1)(2011) 101-107.

[9] C. H. Wang, Z. P. Zhong, R. Li, J. Q. E, Recognition of the flow regimes in the spouted bed based on fuzzy c-means clustering, Powder Technology, 205(1-3) (2011) 201-207.

[10] C. H. Wang, Z. P. Zhong, R. Li, J. Q. E, Prediction of jet penetration depth based on least square support vector machine, Powder Technology, 203(2) ( 2010) 404-411.

[11] P. Lettieri, J. G. Yates, D. Newton, The influence of interparticle forces on the fluidization behaviour of some industrial materials at high temperature, Powder Technol. 110 (2000) 117-127.

[12] H.T. Bi and J.R. Grace, Effects of pressure and temperature on flow regimes in gas-solid fluidization system. Can. J. Chem. Eng. 74 (1996) 1025-1027.

[13] C. Xu, J. X. Zhu, Effects of gas type and temperature on the particle fluidization, China Particuol. 4 (2006) 114-121.

[14] H. J. Subramani, M. B. M. Balaiyya, L. R. Miranda, Minimum fluidization velocity at elevated temperature for Geldart's group-B powders, Exp. Therm. Fluid Sci. 32 (2007) 166-173.

[15] B. Formisani, R. Girimonte, L. Mancuso, Analysis of the fluidization process of particle beds at high temperature, Chem. Eng. Sci. 53 (1997) 951-961. 
[16] Y. Hatate, K. Ohmagari, A. Ikari, K. Kondo, D.F. King, Behavior of bubbles in cylindrical fluidized bed at an elevated temperature, J. Chem. Eng. Jpn. 21 (1988) 424425.

[17] S. Sanaei, N. Mostoufi, R. Radmanesh, R. Sotudeh-Gharebagh, C. Guy, J. Chaouki, Hydrodynamic characteristics of gas-solid fluidization at high temperature, Can. J. Chem. Eng. 88 (2010) 1-11.

[18] M. Nemati, R. Zarghami, N. Mostoufi, Hydrodynamic of high temperature fluidized bed, Chem. Eng. Technol. 8 (2016) 1527-1536.

[19] M. J. Hagh-Shenas-Lari, N. Mostoufi, Effect of temperature on fluidization regimes, Chem. Eng. Technol. 37(2014), 1593-1599.

[20] S. Sasic, B. Leckner, F. Johnsson, F. (2007). Characterization of fluid dynamics of fluidized beds by analysis of pressure fluctuations. Prog. Energy Combust. Sci. 33 (2007) 453-496.

[21] R. Zarghami, N. Mostoufi, R. Sotudeh-Gharebagh Nonlinear Characterization of Pressure Fluctuations in Fluidized Beds, Ind. Eng. Chem. Res. 47 (2008) 9497-9507.

[22] J. M. Hay, B. H. Nelson, C. L. Briens, M. A. Bergougnou, The calculation of the characteristics of a chaotic attractor in a gas-solid fluidized bed, Chem. Eng. Sci. 50 (1995) 373-380.

[23] M. L. van der Stappen, Chaotic hydrodynamics of fluidized beds, Thesis, Delft University Press, Delft, 1996.

[24] F. Johnsson, R. C. Zijerveld, J.C. Schouten, C. M. van den Bleek, B. Leckner, Characterization of fluidization regimes by time-series analysis of pressure fluctuations, Int. J. Multiphase Flow 26 (2000) 663-715. 
[25] J. C. Schouten, F. Takens, C. M. van den Bleek, Estimation of the dimension of a noisy attractor, Phys. Rev. E, 50 (1994) 1851-1861.

[26] N. Marwan, M. Carmen, M. T. J. Kurths, Recurrence plots for the analysis of complex systems, Phys. Rep. 438 (2007) 237-329.

[27] B. Babaei, R. Zarghami, H. Sedighikamal, R. Sotudeh-Gharebagh, N. Mostoufi, Investigating the hydrodynamics of gas-solid bubbling fluidization using recurrence plot, Adv. Powder Technol. 23 (2012) 380-386.

[28] C. Wang, Z. Zhong, E. Jiaqiang, Flow regime recognition in spouted bed based on recurrence plot method, Powder Technol. 219 (2012) 20-28.

[29] H. Sedighikamal and R. Zarghami, Dynamic characteristics of bubbling fluidization through recurrence rate analysis of pressure fluctuations, Particuol. 11 (2013) 282-287

[30] B. Babaei, R. Zarghami, R. Sotudeh-Gharebagh, Monitoring of fluidized beds hydrodynamics using recurrence quantification analysis, AIChE J. 59 (2013) 399-406.

[31] M. Tahmasebpour, R. Zarghami, R. Sotudeh-Gharebagh, N. Mostoufi, Characterization of various structures in gas-solid fluidized beds by recurrence quantification analysis, Particuol. 11 (2012) 647-656.

[32] M. Tahmasebpoor, R. Zarghami, R. Sotudeh-Gharebagh, N. Mostoufi, Characterization of fluidized beds hydrodynamics by recurrence quantification analysis and wavelet transform, Int. J. Multiphase Flow 69 (2015) 31-41

[33] J. P. Eckmann, S. O. Kamphorst, D. Ruelle, Recurrence plots of dynamical systems, Europhys. Lett. 4 (1987) 973-977 
[34] C. L. Webber and J. P. Zbilut, Recurrence quantification analysis of nonlinear dynamical systems, in: M. A. Riley, G. van Orden (Eds.), Tutorials in Contemporary Nonlinear Methods for the Behavioral Sciences, National Science Foundation, 2005, pp. 26-94

[35] B. Babaei, R. Zarghami, H. Sedighikamal, R. Sotudeh-Gharebagh, N. Mostoufi, Selection of minimal length of line in recurrence quantification analysis, Physica A 395 (2014) $112-120$.

[36] J. van der Schaaf, J. C. Schouten, F. Johnsson, C. M. van den Bleek, Non-intrusive determination of bubble and slug length scales in fluidized beds by decomposition of the power spectral density of pressure time series. Int. J. Multiphase Flow 28 (2002) 865-880.

[37] R. C. Darton, R. D. La Nauze, J. F. Davidson, and D. Harrison, Bubble growth due to coalescence in fluidised beds. Transactions of the Institution of Chemical Engineers. 55 (1977) 274-280.

[38] F. K. van Willigen, J. R. van Ommen, J. van Turnhout, C. M. van den Bleek, Bubble Size Reduction in a Fluidized Bed by Electric Fields. International Journal of Chemical Reactor Engineering. 1(1) (2003) 1542-6580.

[39] M. Abbasi, R. Sotudeh-Gharebagh, N. Mostoufi, M. J. Mahjoob, Non-intrusive monitoring of bubbles in a gas-solid fluidized bed using vibration signature analysis, Powder Technol. 196 (2009) 278-285

[40] P. Ahuja, H. Agrawal, A. K. Sethi, U. Raj, Chaotic analysis of pressure fluctuations in gas-solid fluidized bed, Indian J. Chem. Techn. 12 (2005) 212-219.

[41] H. Kantz and T. Schreiber, Nonlinear time series analysis, second ed., Cambridge University Press, New York, 2004. 
[42] J. R. van Ommen, J. van der Schaaf, J. C. Schouten, B. G. M. van Wachem, M. O. Coppens, C. M. and van den Bleek, Optimal placement of probes for dynamic pressure measurements in large-scale fluidized beds, Powder Technol. 139 (2004) 264-276.

[43] G. S. Lee and S. D. Kim, Pressure fluctuations in turbulent fluidized beds, J. Chem. Eng. Japan. 21 (1988) 515-521, 1988.

[44] A. Chen and H. T. Bi, Pressure fluctuations and transition from bubbling to turbulent fluidization, Powder Technol. 133 (2003) 237-246

[45] T. Y. Yang and L. Leu, Study of transition velocities from bubbling to turbulent fluidization by statistic and wavelet multi-resolution analysis on absolute pressure fluctuations, Chem. Eng. Sci. 63 (2008) 1950-1970.

[46] J. van der Schaaf, J. C. Schouten, and C. M. van den Bleek, Origin, propagation and attenuation of pressure waves in gas-solid fluidized beds, Powder Technol. 95 (1998) 220-233.

[47] H. T. Bi and J. R. Grace, Effects of measurement method on velocities used to demarcate the transition to turbulent fluidization, Chem. Eng. J. 57 (1995) 261-271.

[48] P. Cai, Y. Jin, Z. Q. Yu, Z. W. Wang, Mechanism of flow regime transition from bubbling to turbulent fluidization, AIChE J. 36 (1990) 955-956.

[49] H. T. Bi, J. R. Grace, K. S. Lim, Transition from bubbling to turbulent fluidization, Ind. Chem. Res. Dev. 34 (1995) 4003-4008 


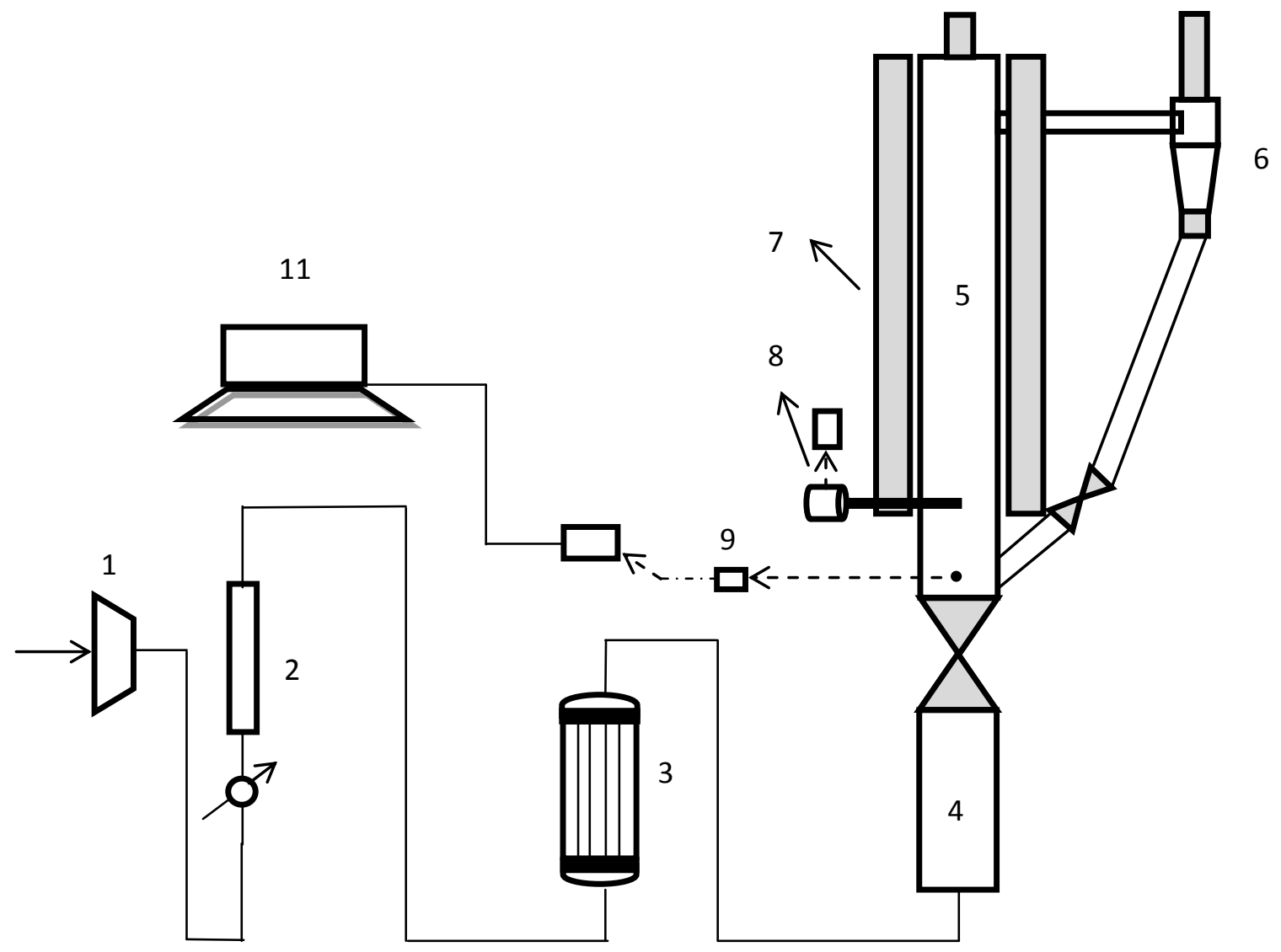

Figure 1. Schematic of experimental setup: (1) air compressor, (2) mass flow controller, (3) preheater, (4) main heater, (5) fluidized bed, (6) cyclone, (7) insulation, (8) thermocouple, (9) pressure sensor, (10) analog to digital converter, (11) computer 


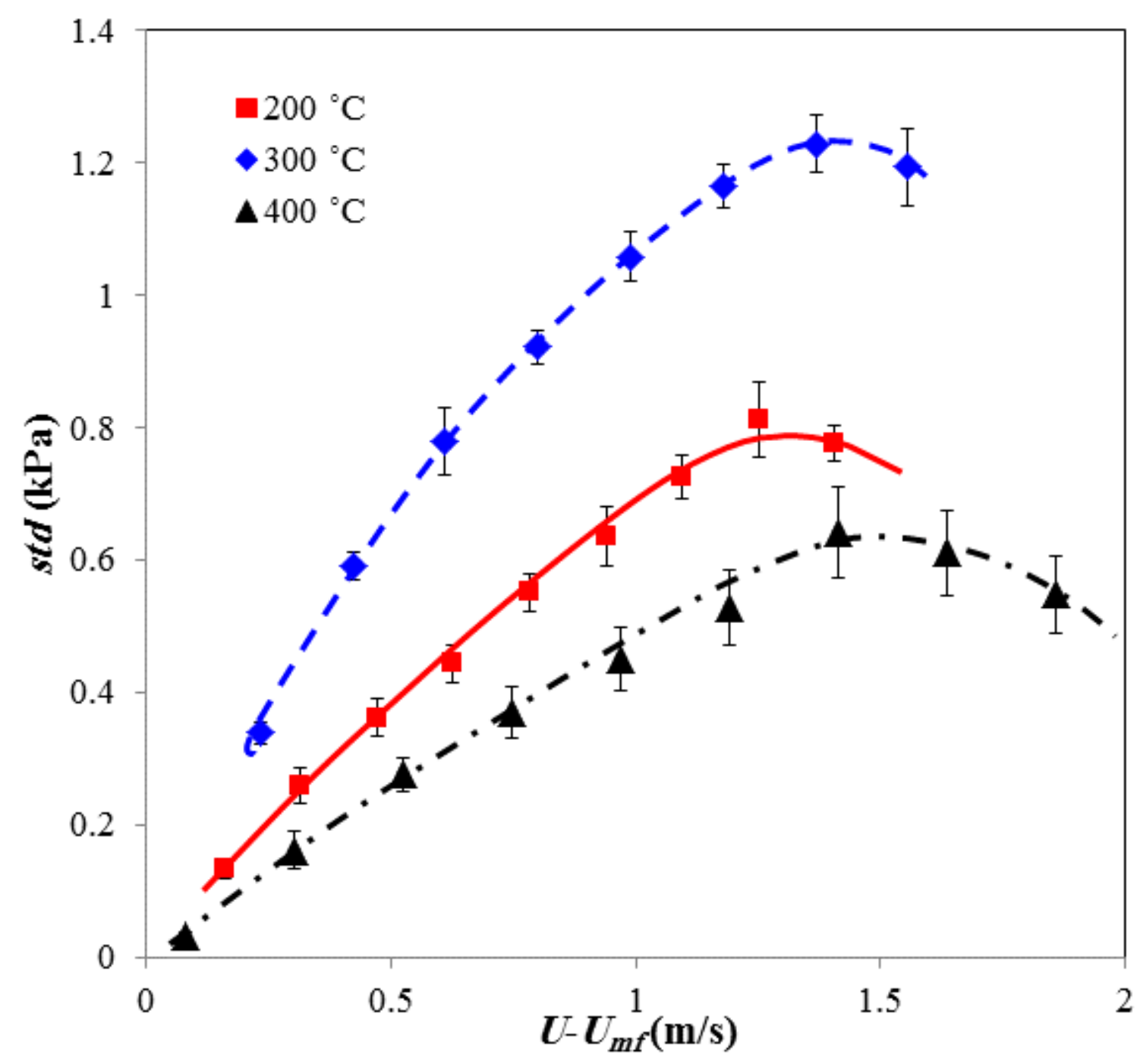

Figure 2. Standard deviation of pressure fluctuations versus gas velocity at different temperature in the bed of $420 \mu \mathrm{m}$ particles; measurement position was $5 \mathrm{~cm}$ above distributor. 


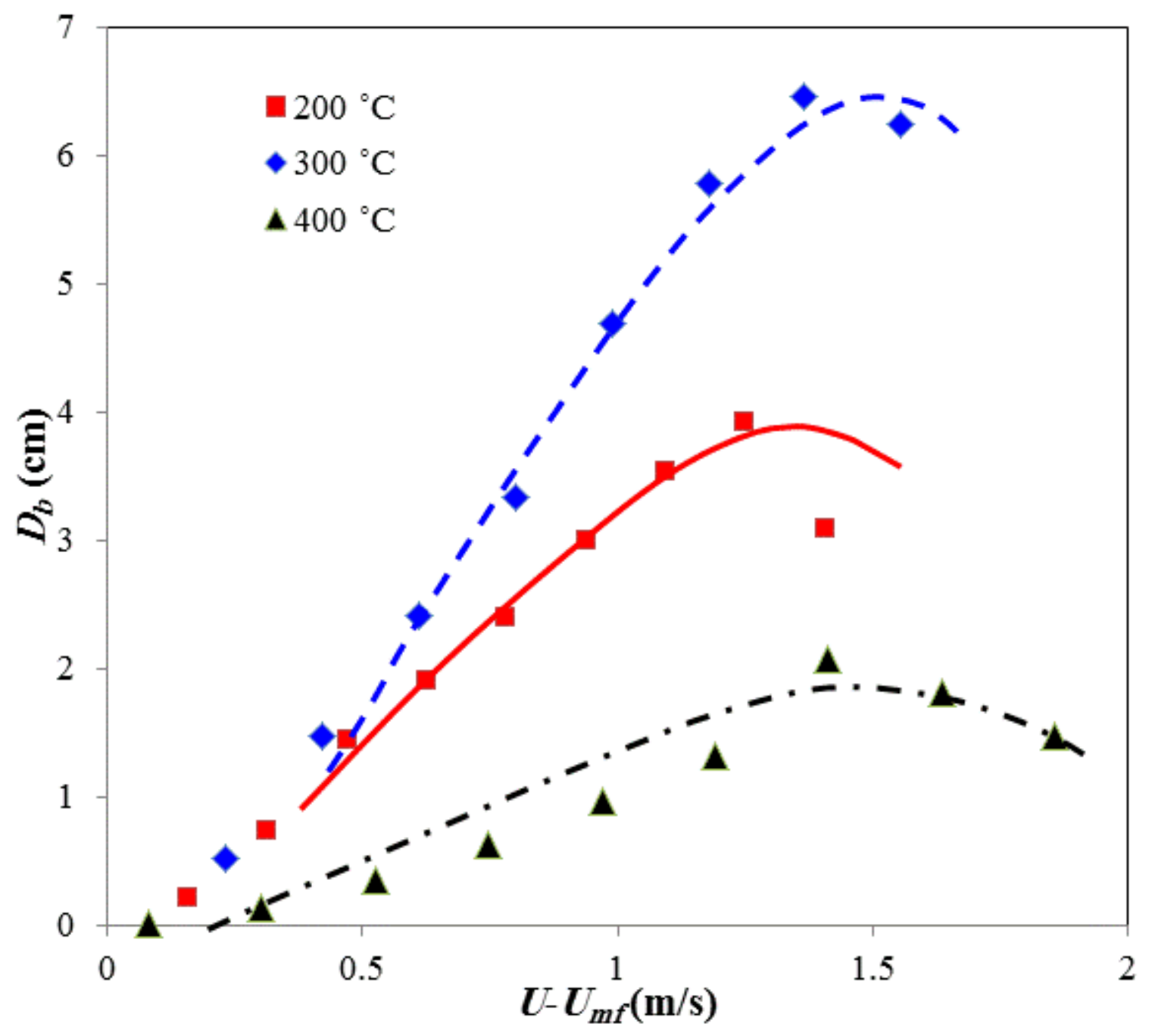

Figure 3. Estimated bubble diameter versus gas velocity at various temperatures in the bed of $420 \mu \mathrm{m}$ particles; measurement position was $5 \mathrm{~cm}$ above distributor. 


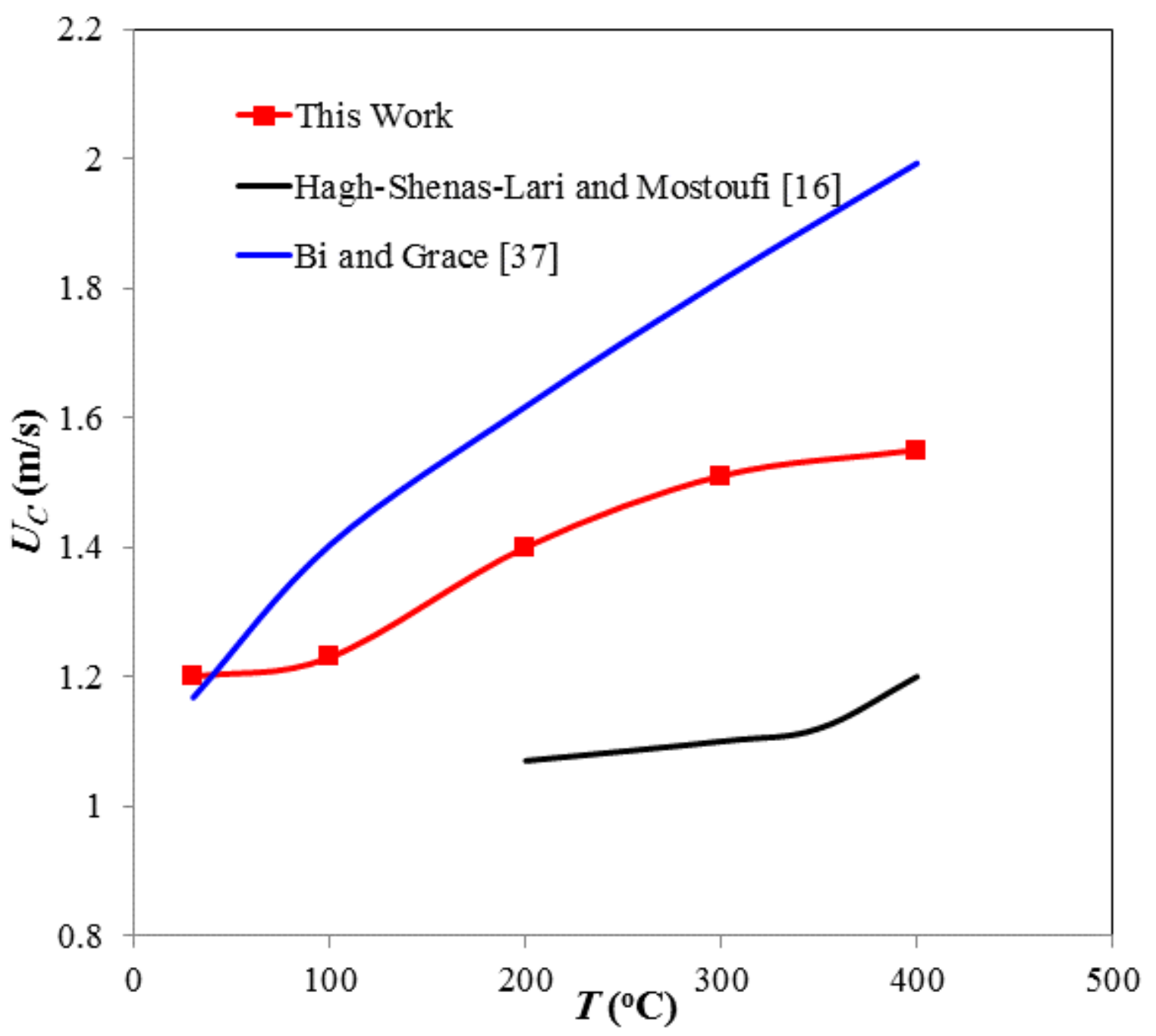

Figure 4. Effect of temperature on $U_{c}$ in the bed of $420 \mu \mathrm{m}$ particles; measurement position was $5 \mathrm{~cm}$ above distributor 
(a)

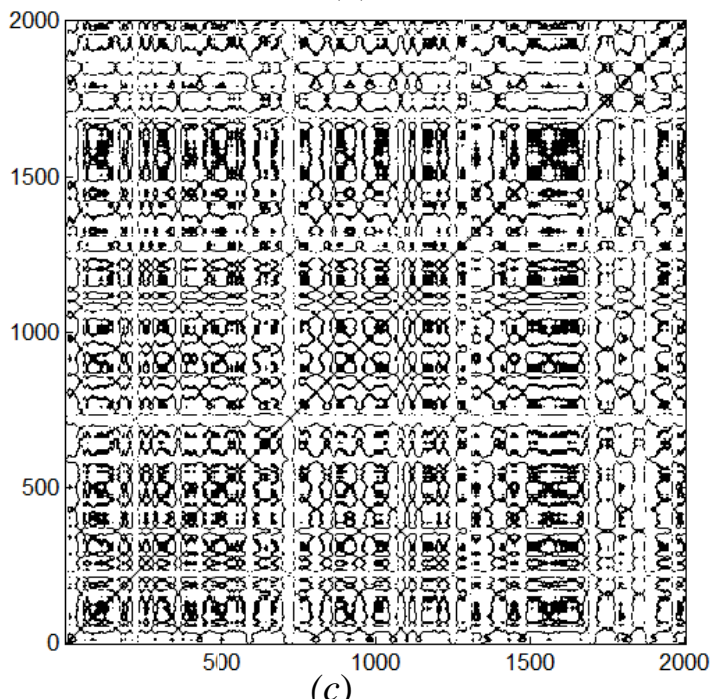
(c)

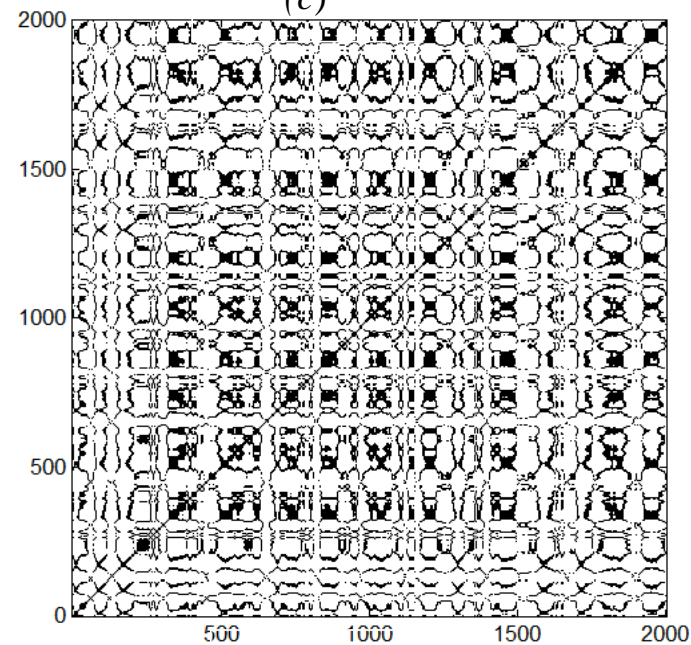

(e) (b)

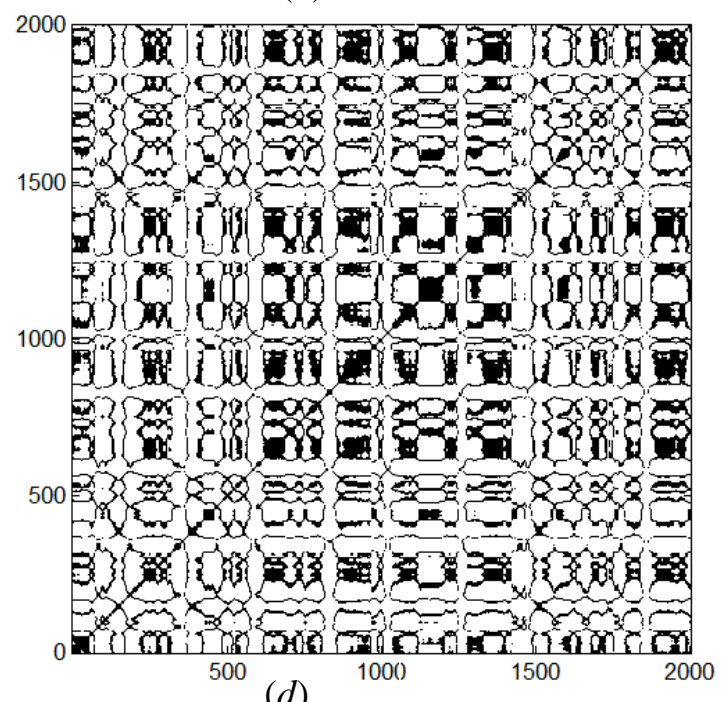

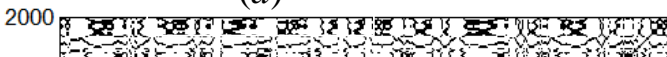

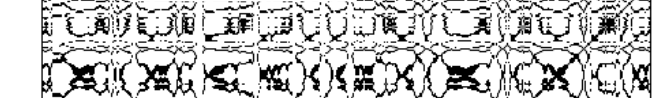

(n)

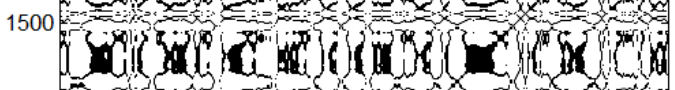

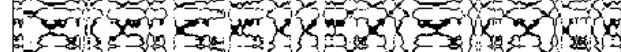

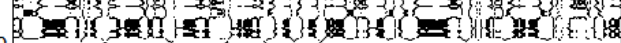

$1000=0.00 \%$

$=0 \times x \times x=0 \times x$

B

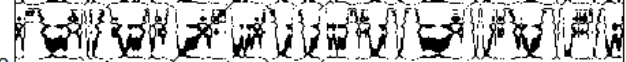

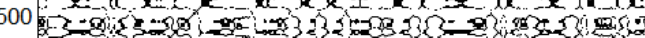

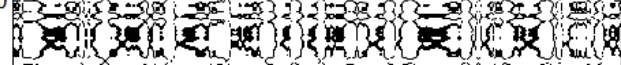

J

(f) 


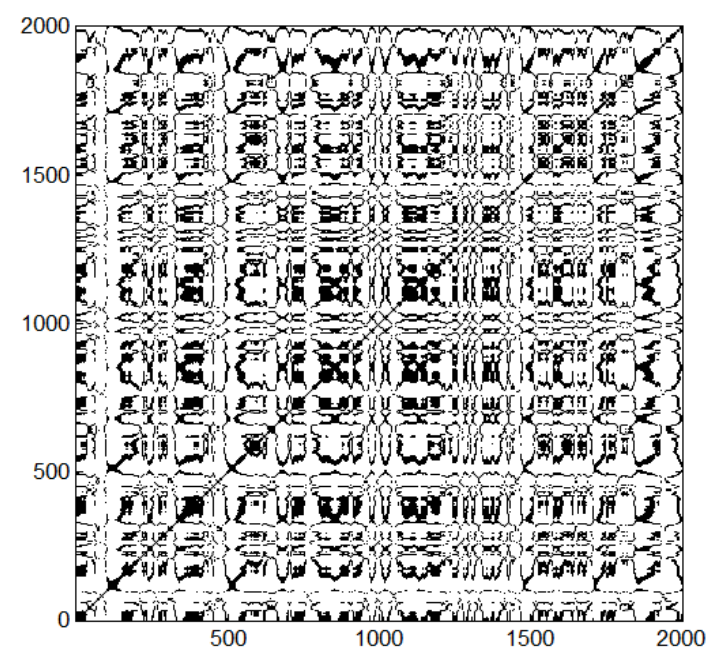

$(g)$

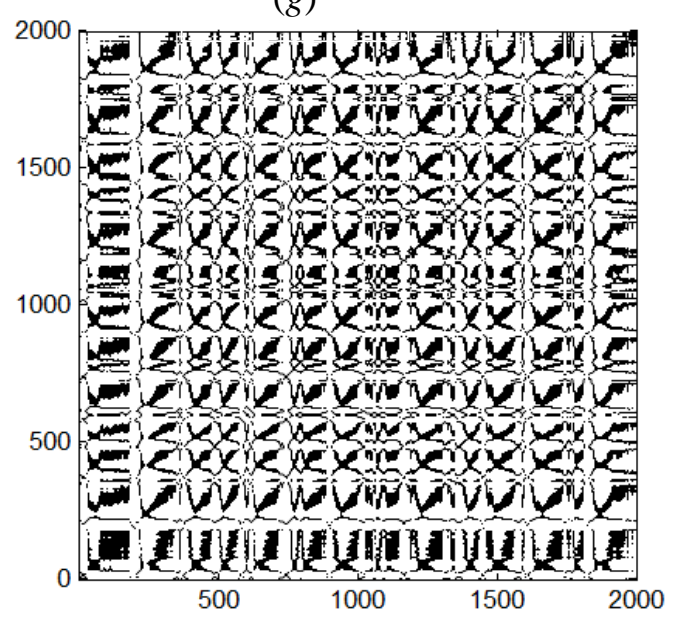

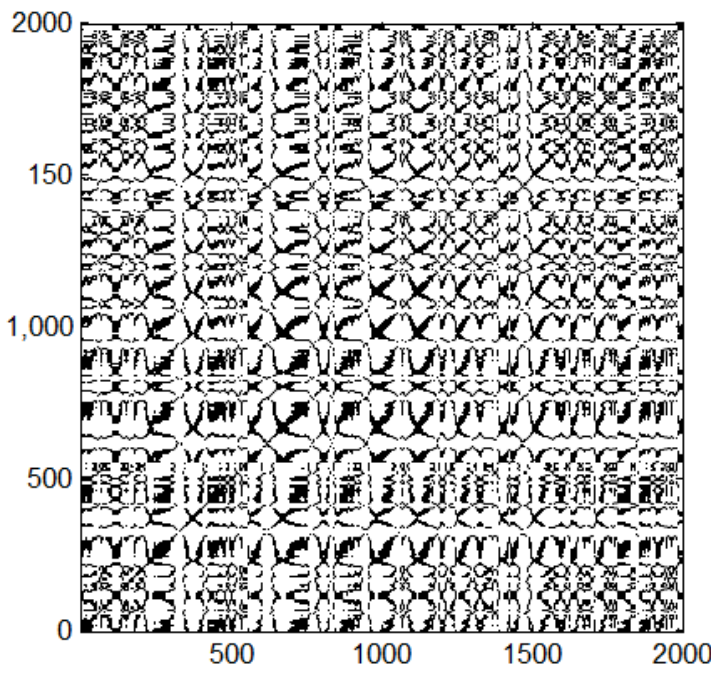

$(h)$

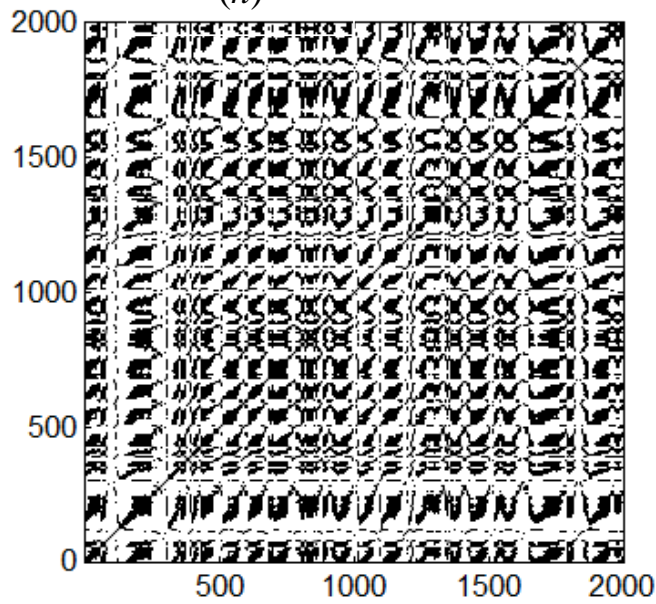

Figure 5. Recurrence plot of the fluidized bed at superficial gas velocities of (a) $0.38 \mathrm{~m} / \mathrm{s}$, (b) $0.57 \mathrm{~m} / \mathrm{s}$, (c) $0.76 \mathrm{~m} / \mathrm{s}$, (d) $0.95 \mathrm{~m} / \mathrm{s}$, (e) $1.13 \mathrm{~m} / \mathrm{s}$, (f) $1.32 \mathrm{~m} / \mathrm{s}$, (g) $1.51 \mathrm{~m} / \mathrm{s}$, and (h) $1.70 \mathrm{~m} / \mathrm{s}$; N=2000; $\varepsilon=0.4$; 
(a)

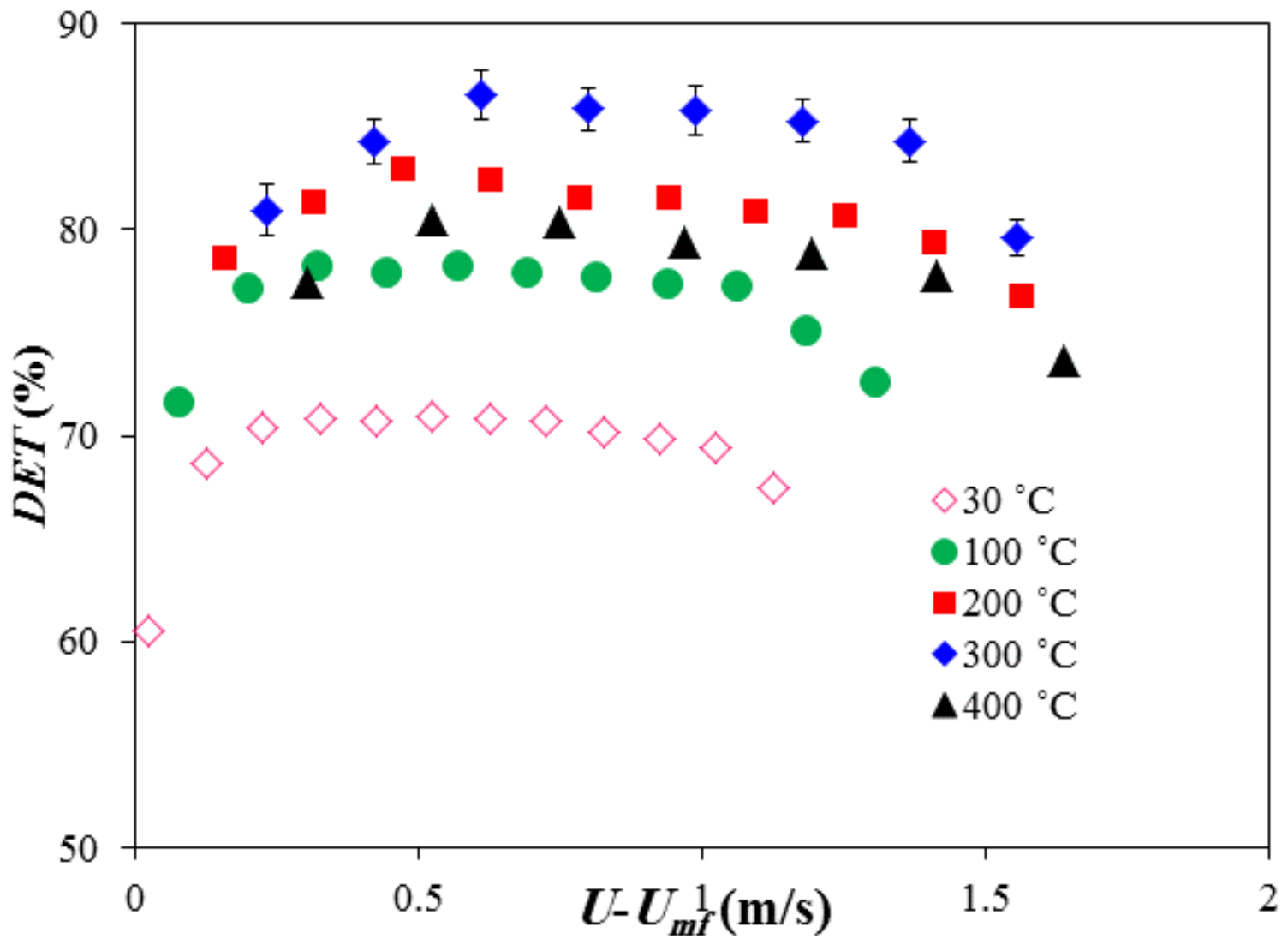

(b)

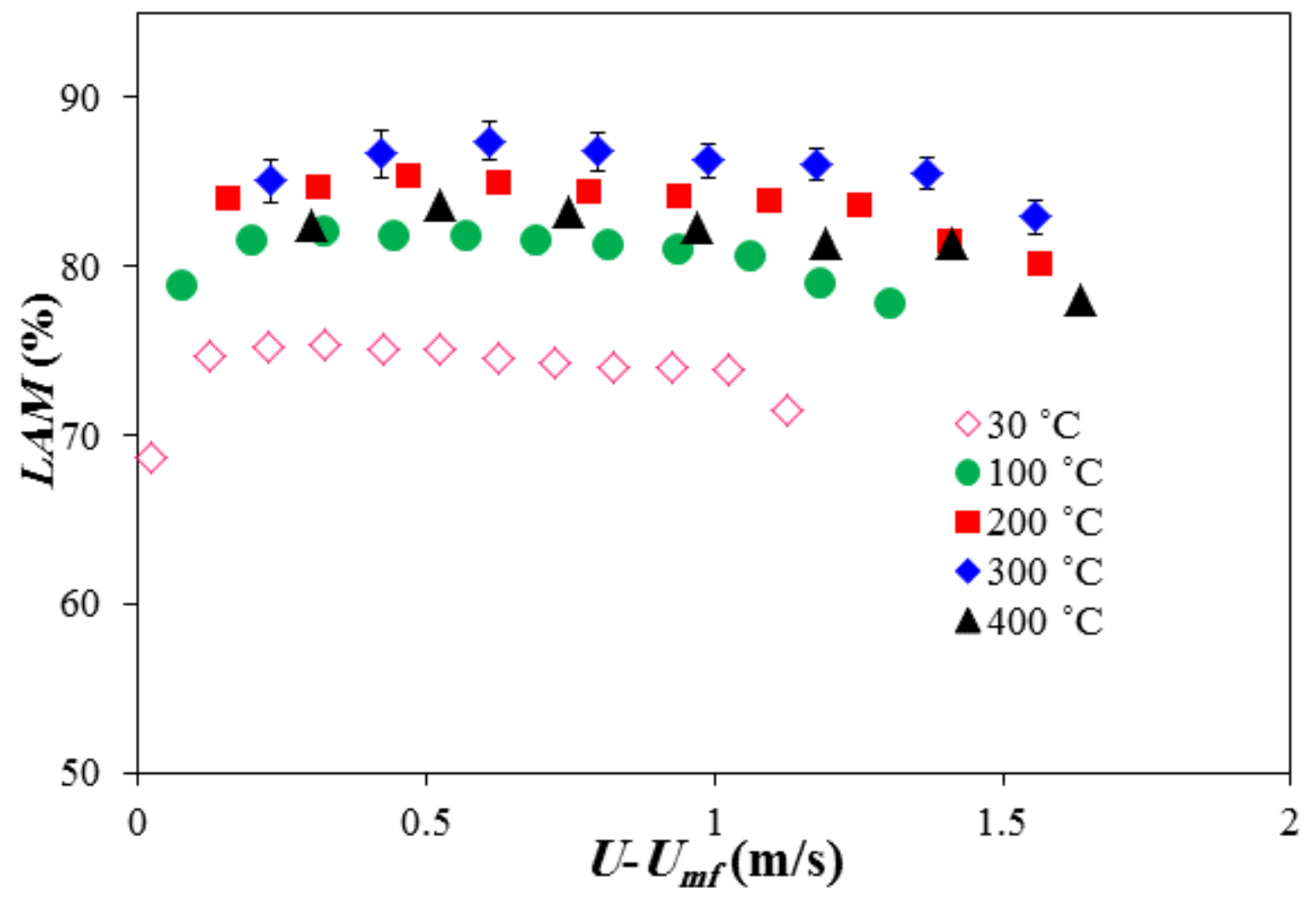


(c)

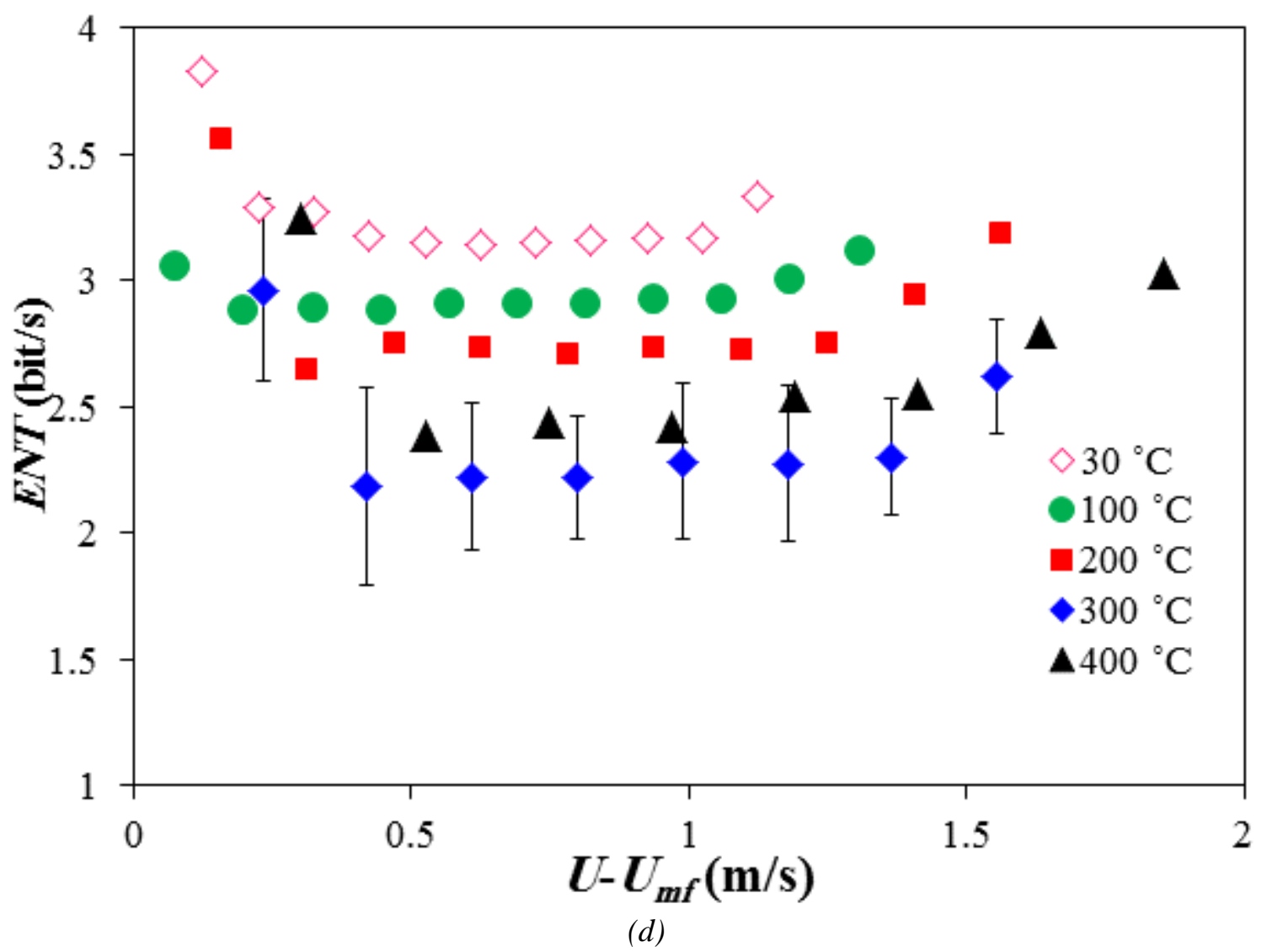




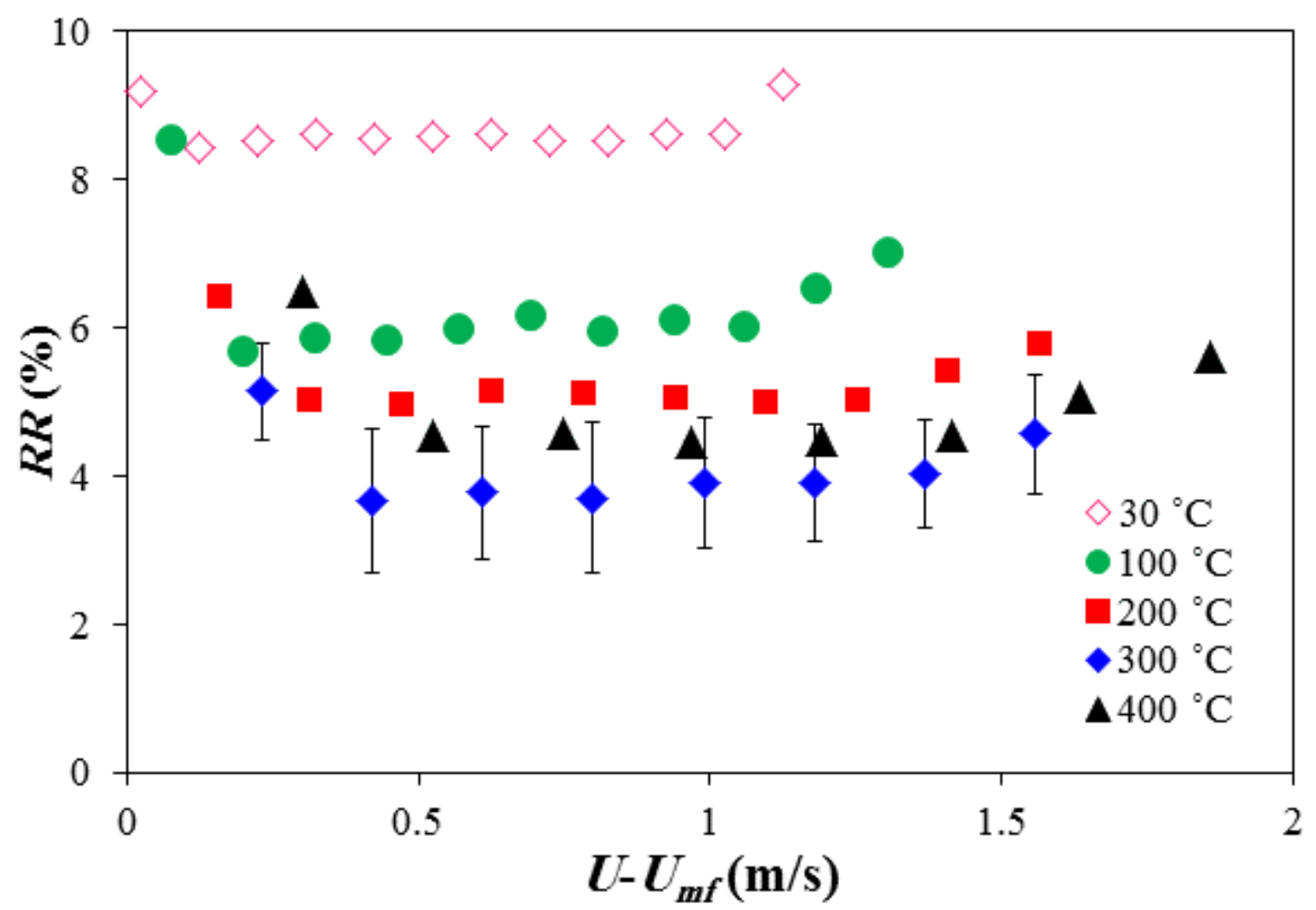

Figure 6. RQA parameters versus gas velocity at various temperatures (a) determinism, (b) laminarity, (c) entropy, and (d) recurrence rate; $\mathrm{L} / \mathrm{D}=1.5 ; 420 \mu \mathrm{m}$ particles; measurement position was $5 \mathrm{~cm}$ above distributor 


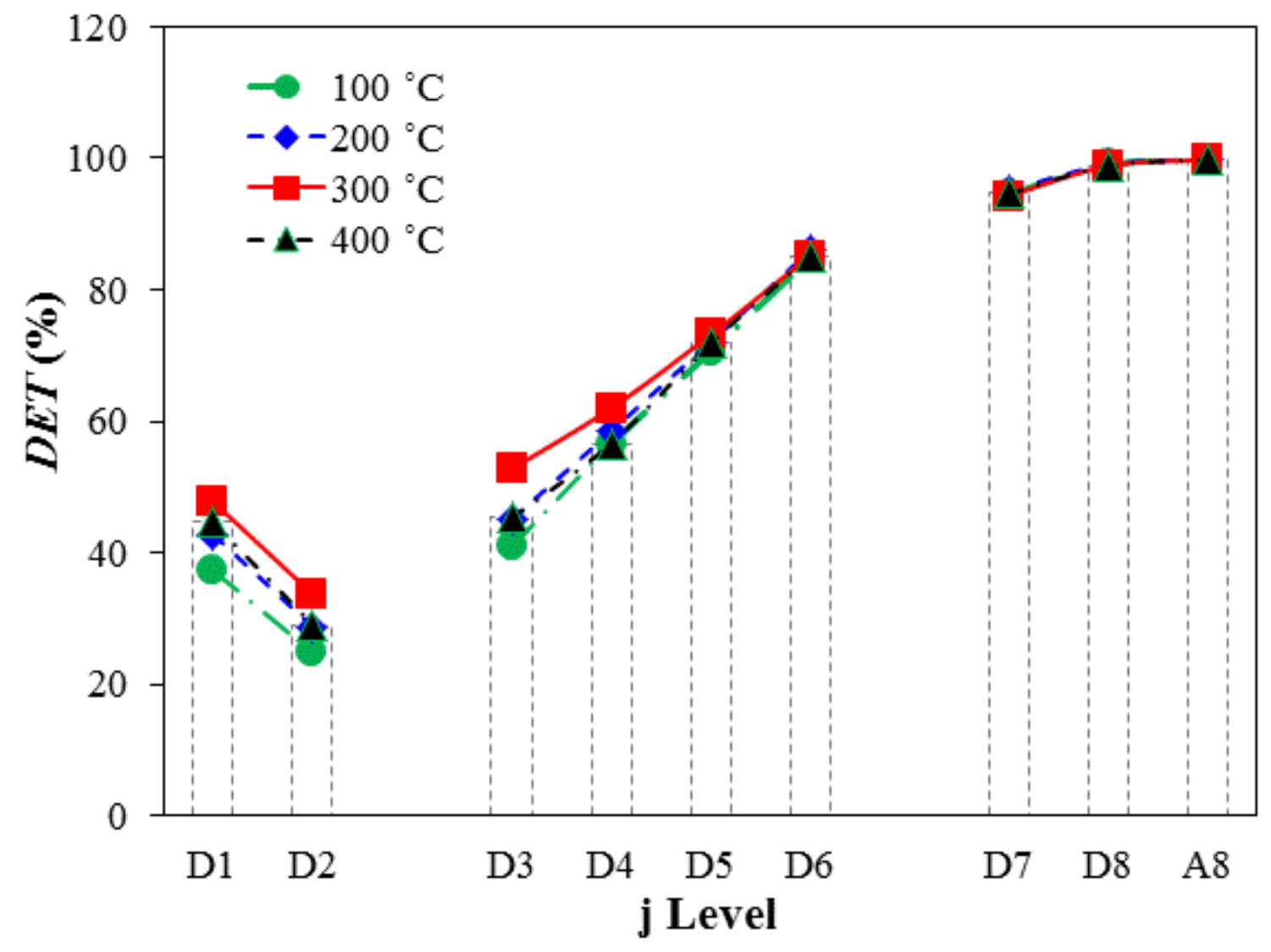

Figure 7. Determinism of pressure fluctuations at various temperatures and decomposition levels at $U=0.6$ $\mathrm{m} / \mathrm{s}, L / D=1.5,420 \mu \mathrm{m}$ particles, measurement position was $5 \mathrm{~cm}$ above the distributor. 
Figu

re 8.

RP

of

mac

ro,

mes

o,

micr

o

stru

ctur

es

and

mai

$\mathrm{n}$

sign

al

for

420

$\mu \mathrm{m}$

sand

parti

cles

at

300

${ }^{\circ} \mathrm{C}$,

$U=0$

.95

$\mathrm{m} / \mathrm{s}$

and

$L / D$

$=1.5$

;

mea

sure

men

$\mathrm{t}$

posi

tion
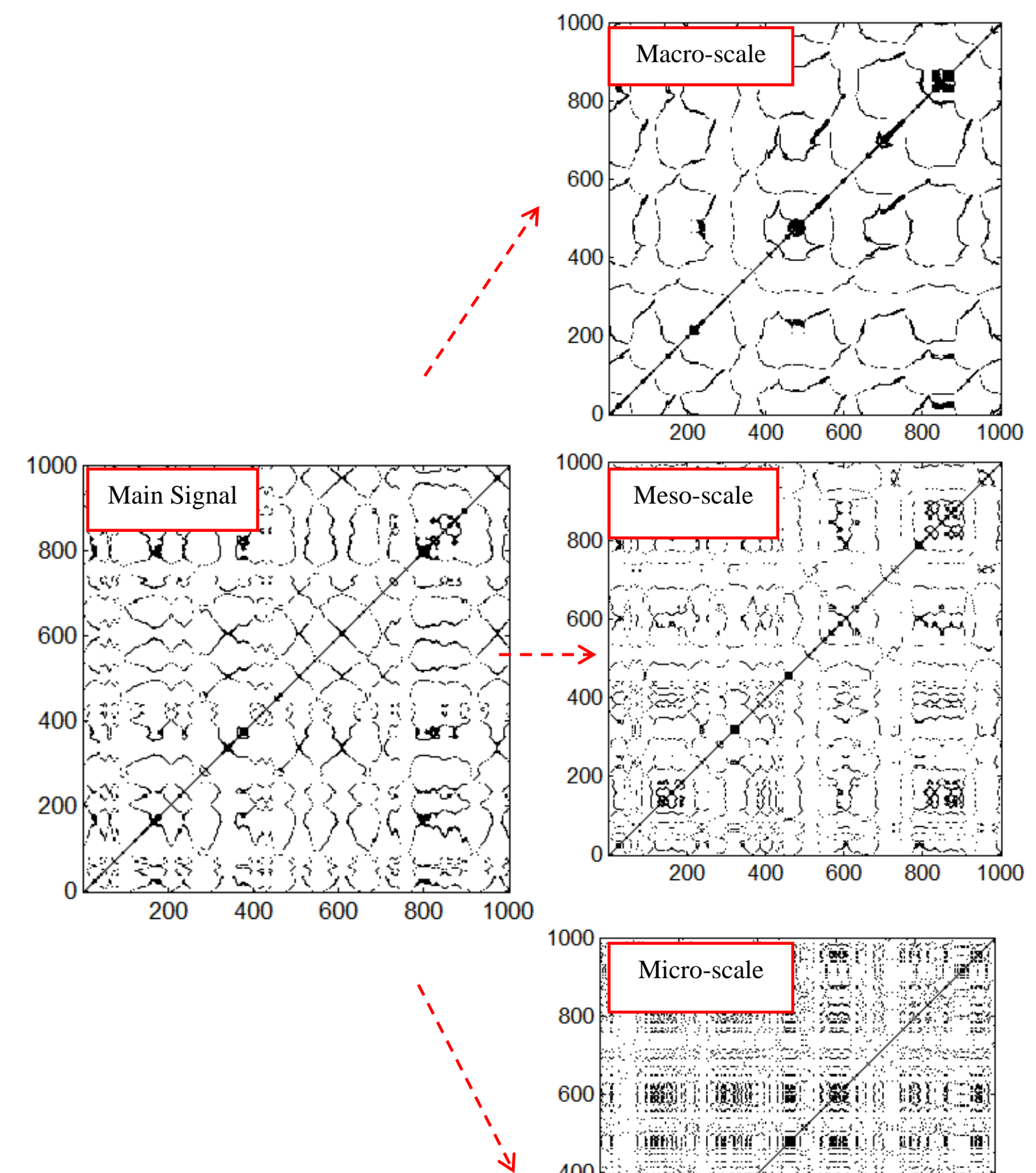

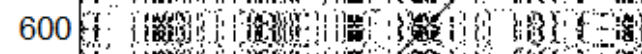

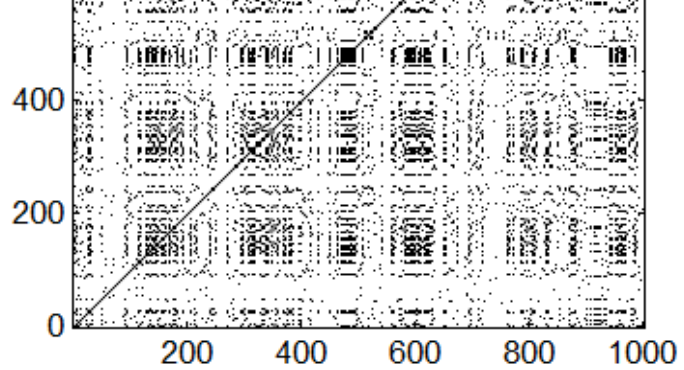

was $5 \mathrm{~cm}$ above distributor. 
(a)

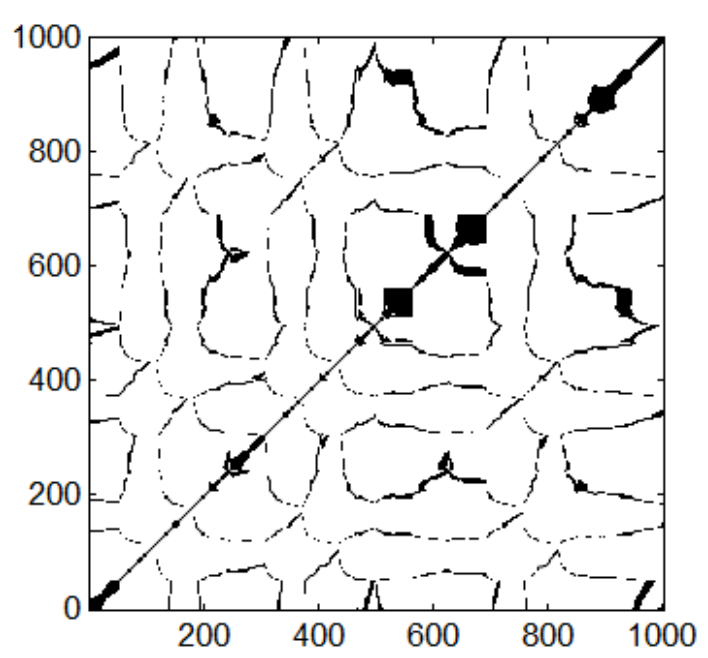

(b)

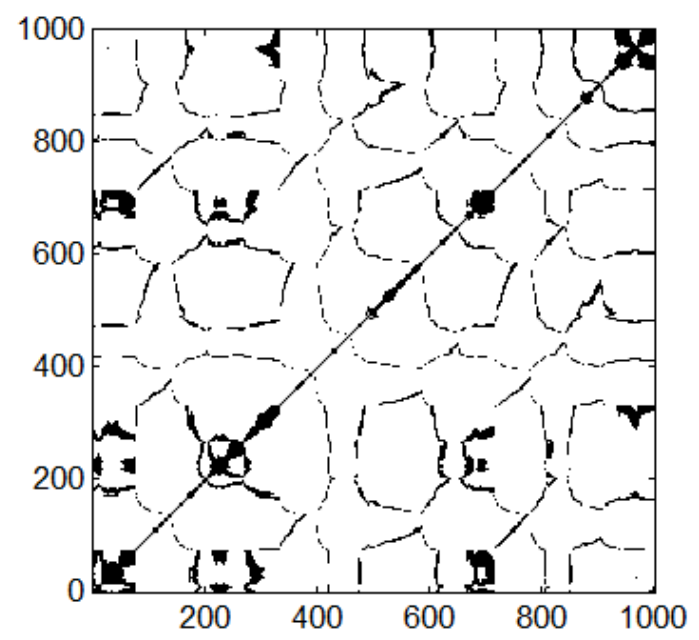

(c) 


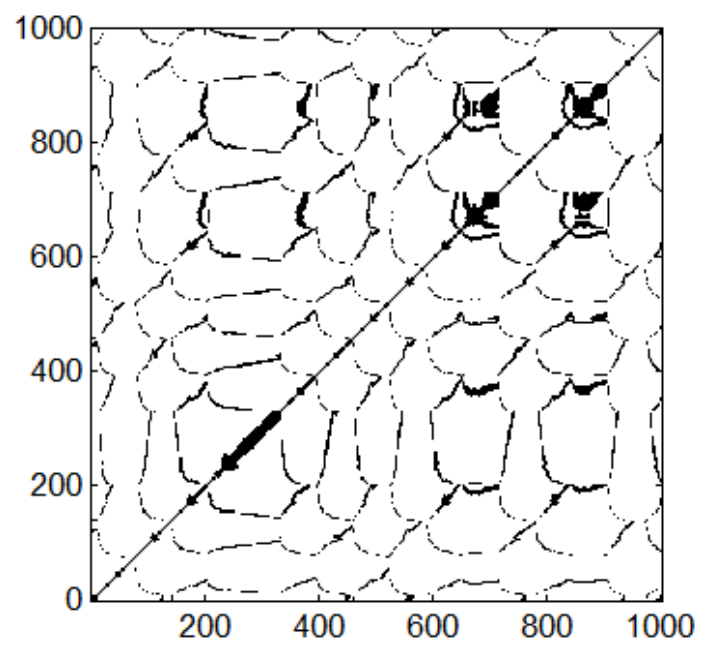

Figure 9. RPs of macro structure at (a) $200{ }^{\circ} \mathrm{C}$, (b) $300{ }^{\circ} \mathrm{C}$, and (c) $400{ }^{\circ} \mathrm{C} ; U=0.5 \mathrm{~m} / \mathrm{s} ; 420 \mu \mathrm{m}$ particles; $L / D=1.5$

(a)

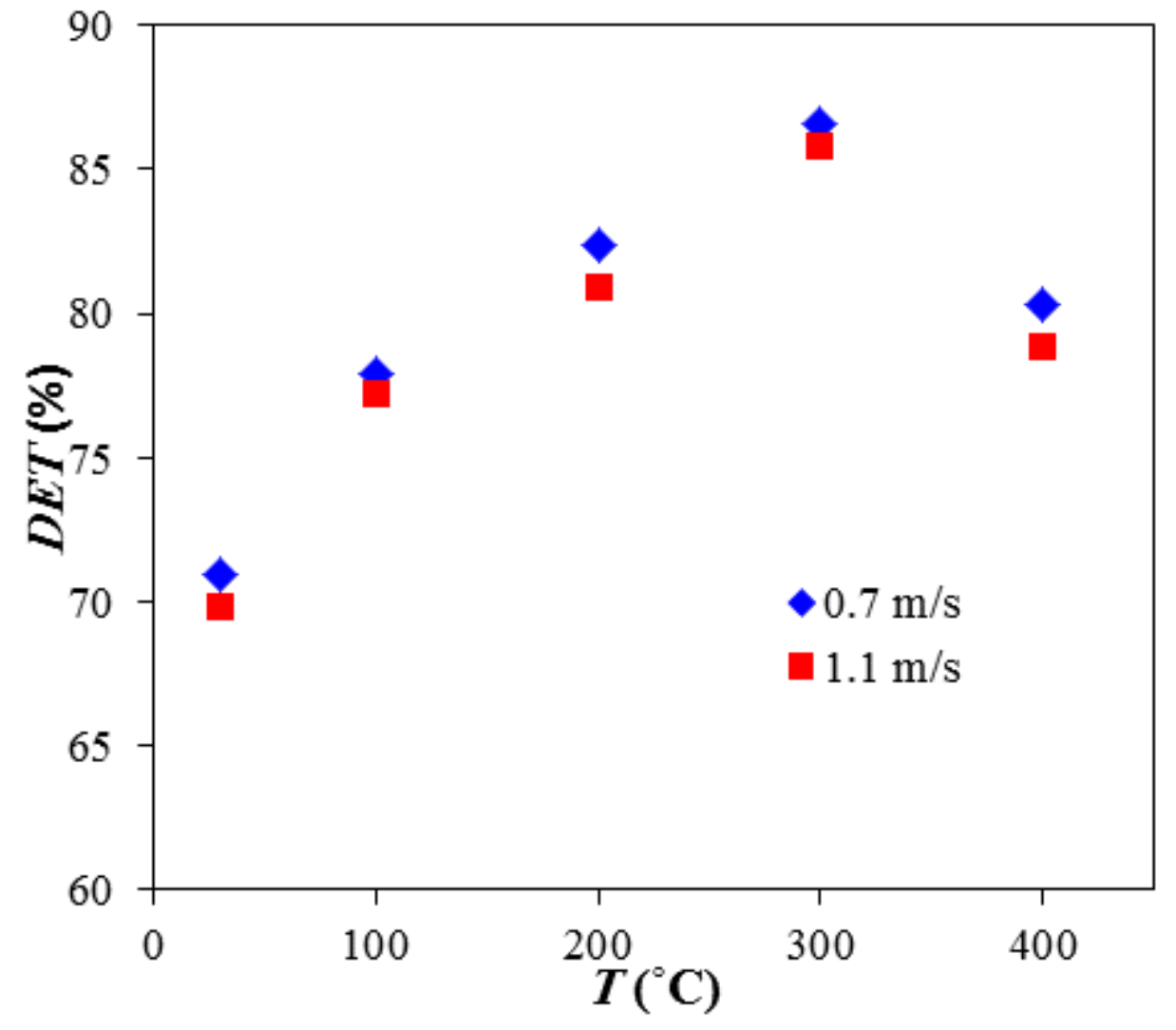

(b) 


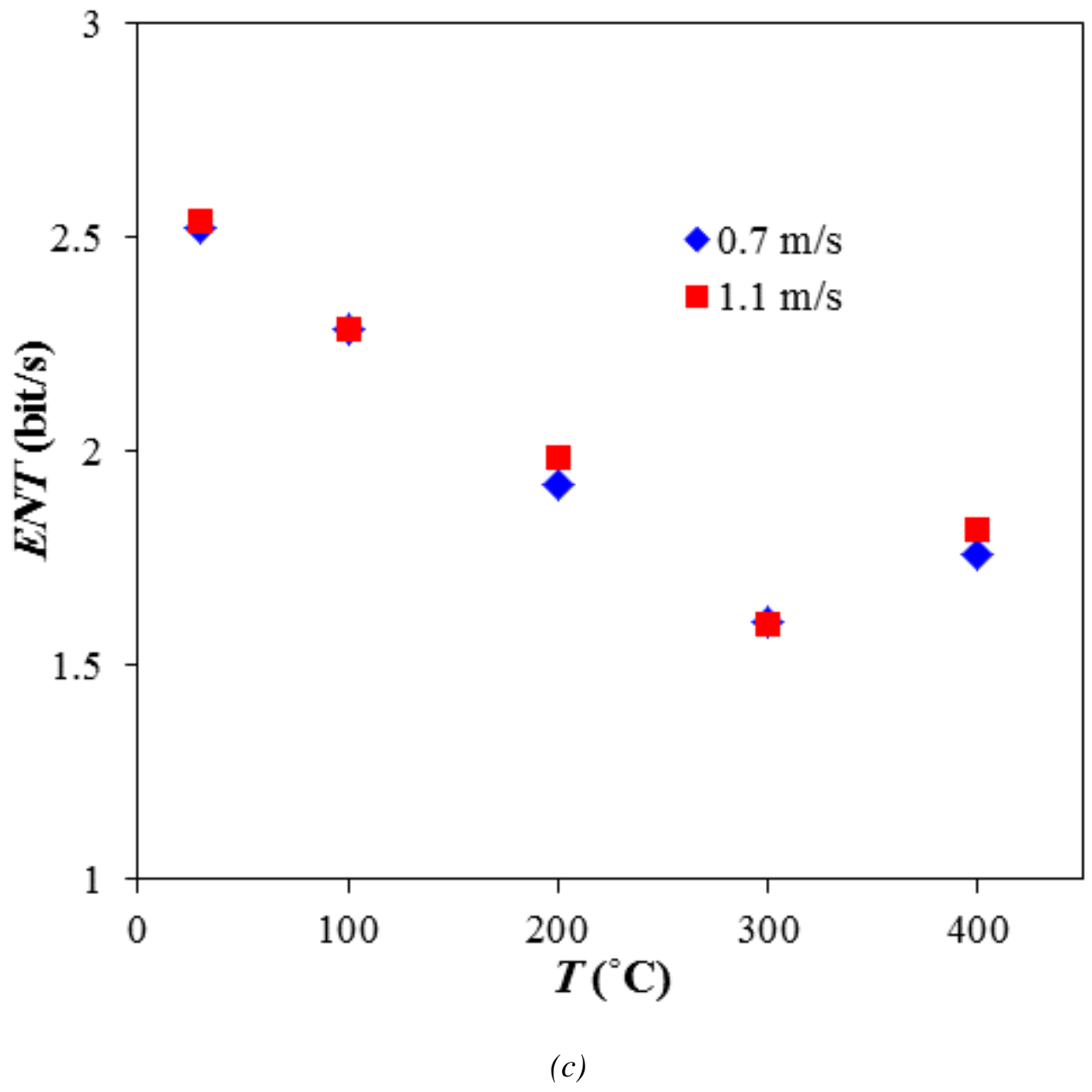




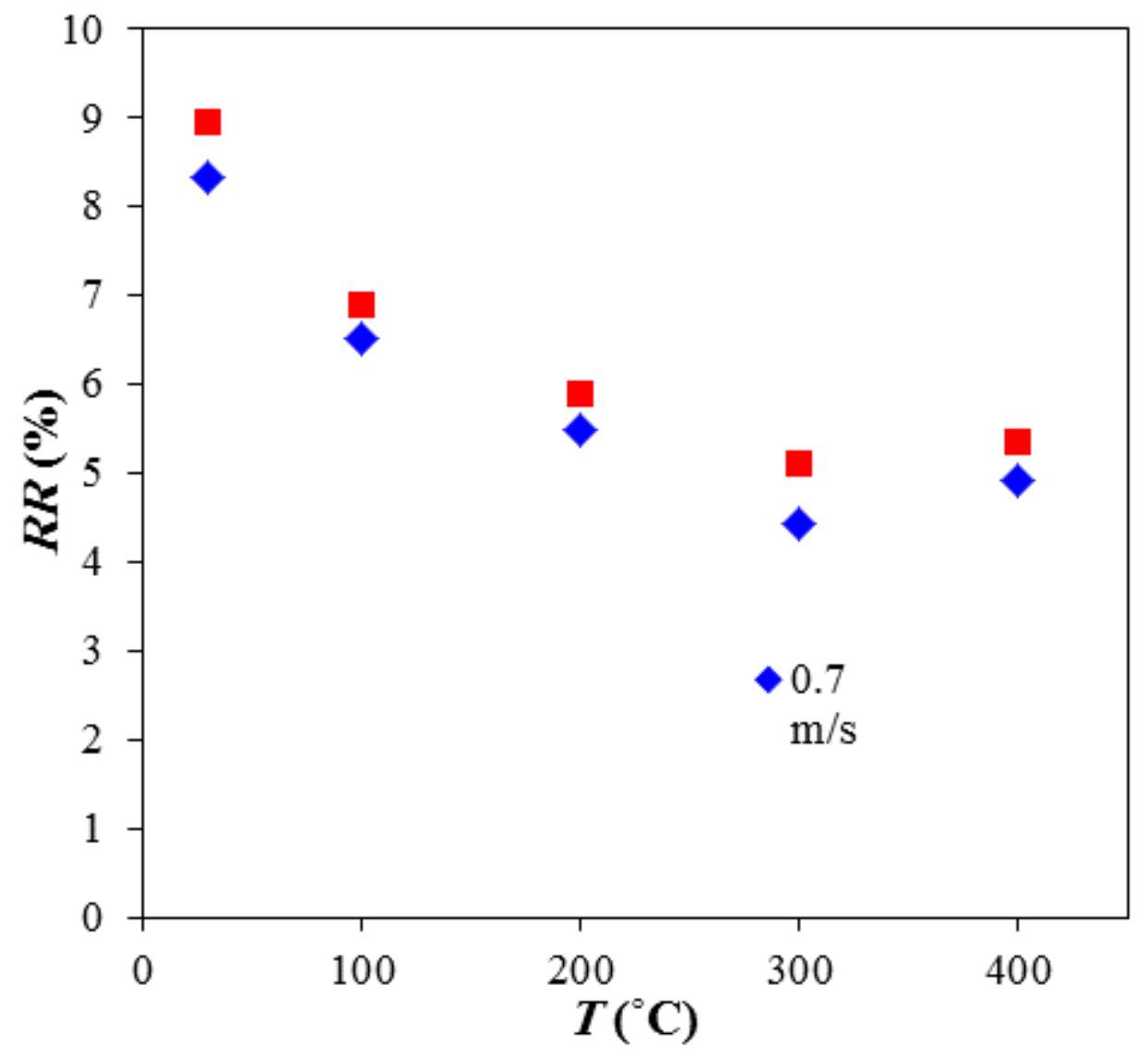

(d)

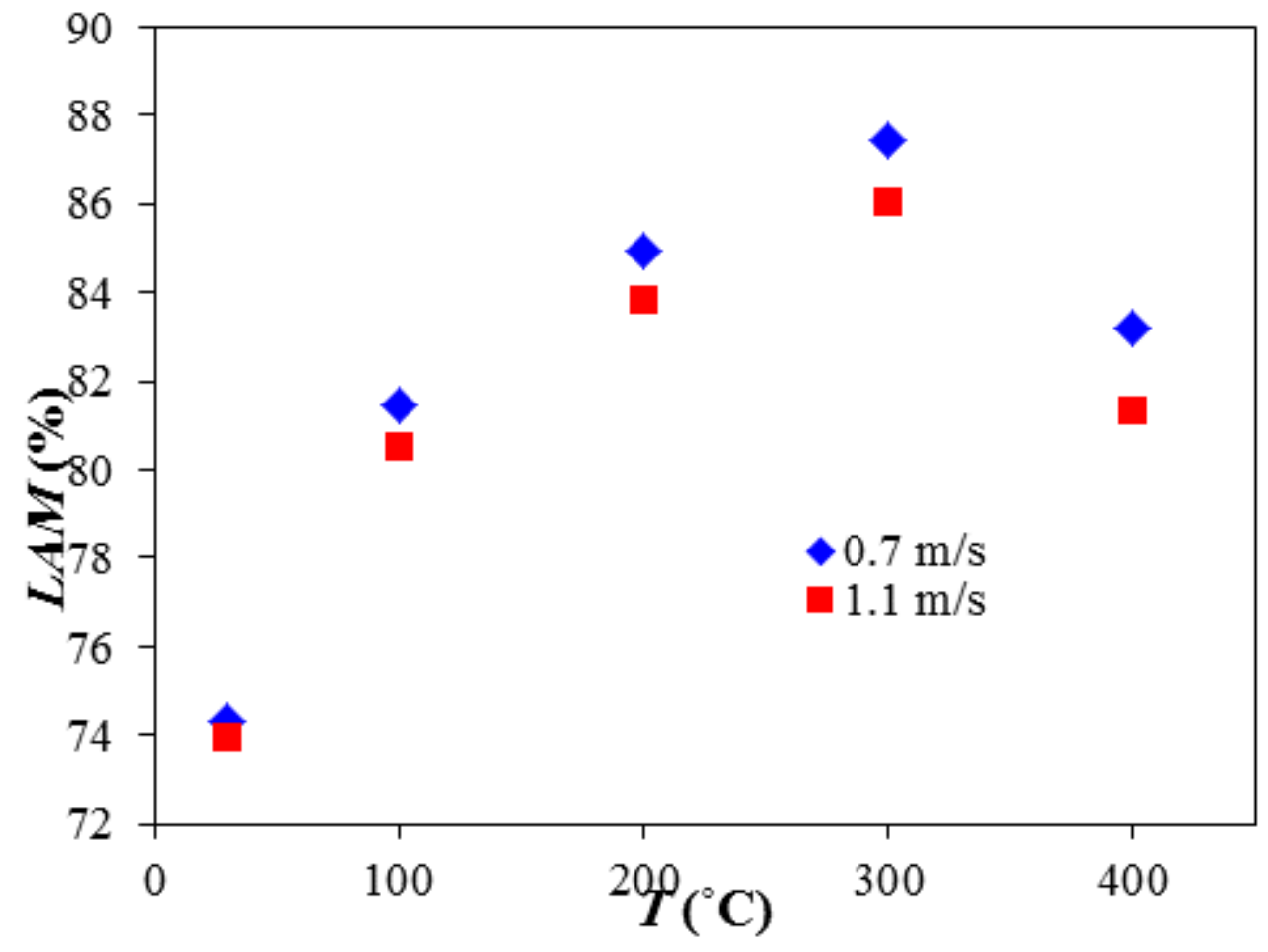


Figure 10. RQA parameters at various temperatures and gas velocities (a) determinism, (b) entropy, (c) recurrence rate, and (d) laminarity

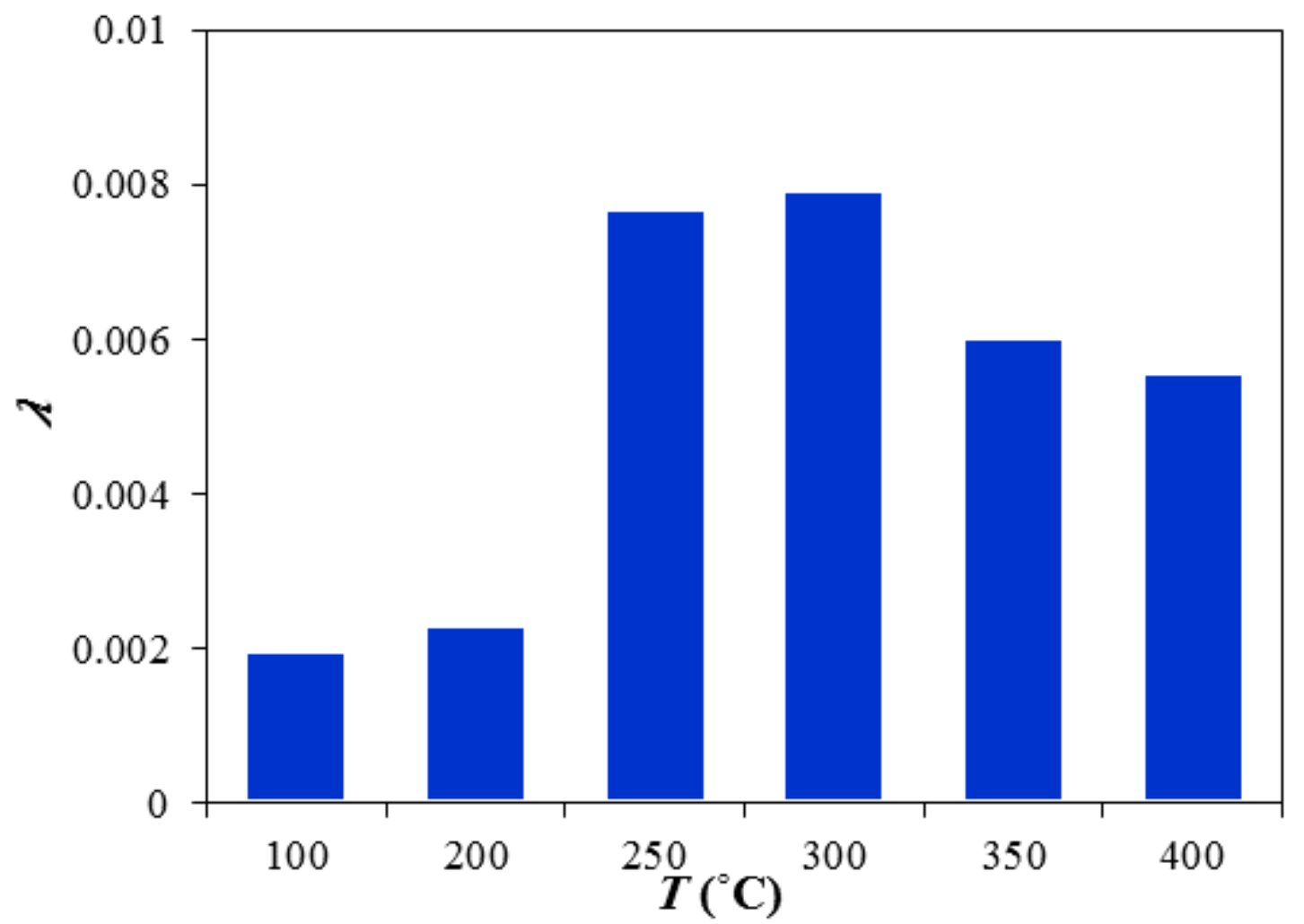

Figure 11. Lyapunov exponent versus temperature at $U=0.6 \mathrm{~m} / \mathrm{s} ; L / D=1.5$; measurement position was $5 \mathrm{~cm}$ above distributor 
Table1. Solids properties at $25^{\circ} \mathrm{C}$

\begin{tabular}{cccccc}
\hline Solids & $\bar{d}_{p}[\mu \mathrm{m}]$ & $\rho_{p}\left[\mathrm{~kg} / \mathrm{m}^{3}\right]$ & Geldart Group & $U_{m f}[\mathrm{~m} / \mathrm{s}]$ & $U_{c}[\mathrm{~m} / \mathrm{s}]$ \\
\hline Sand & 420 & 2640 & B & 0.182 & 1.29 \\
\hline
\end{tabular}




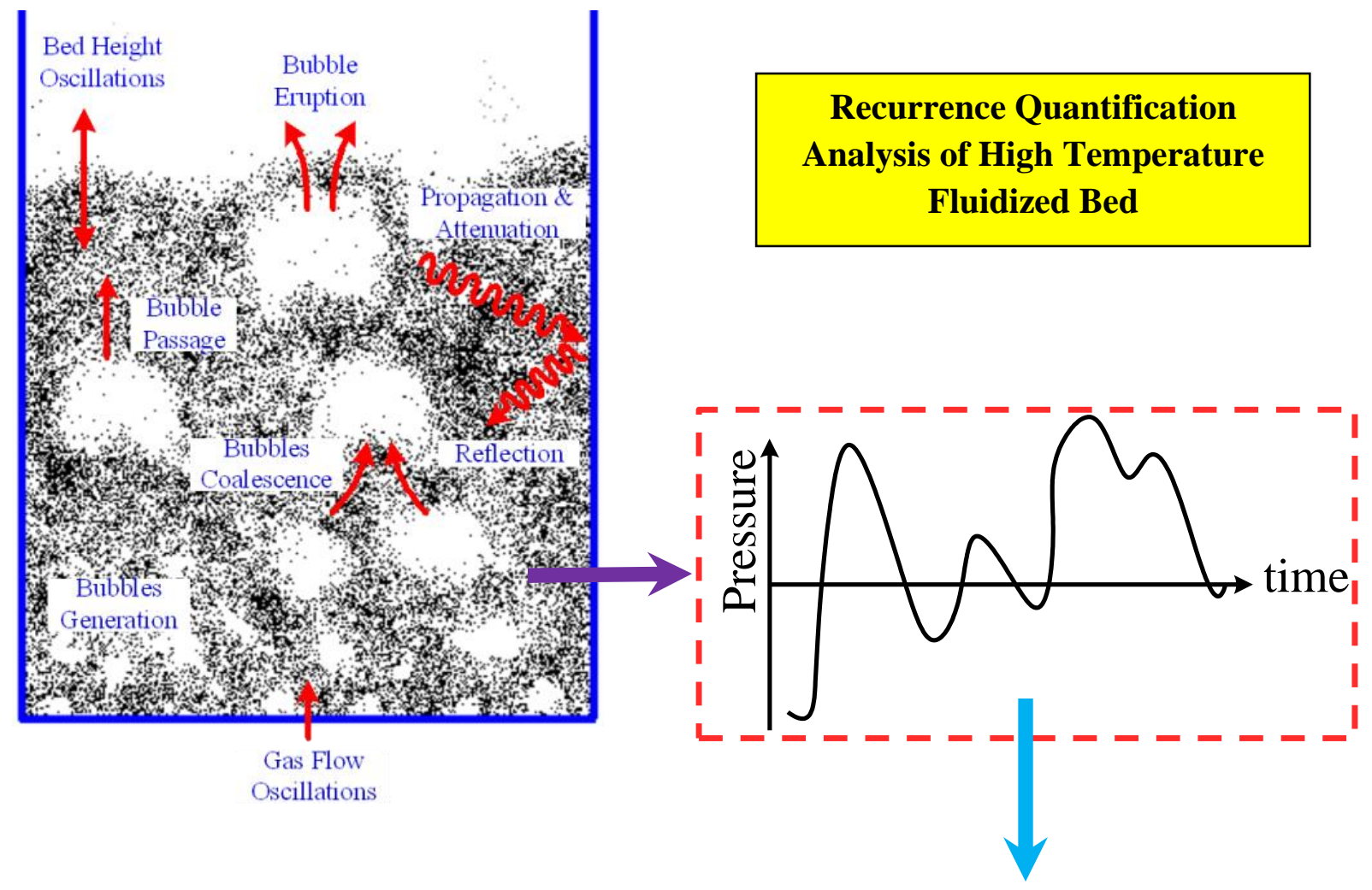




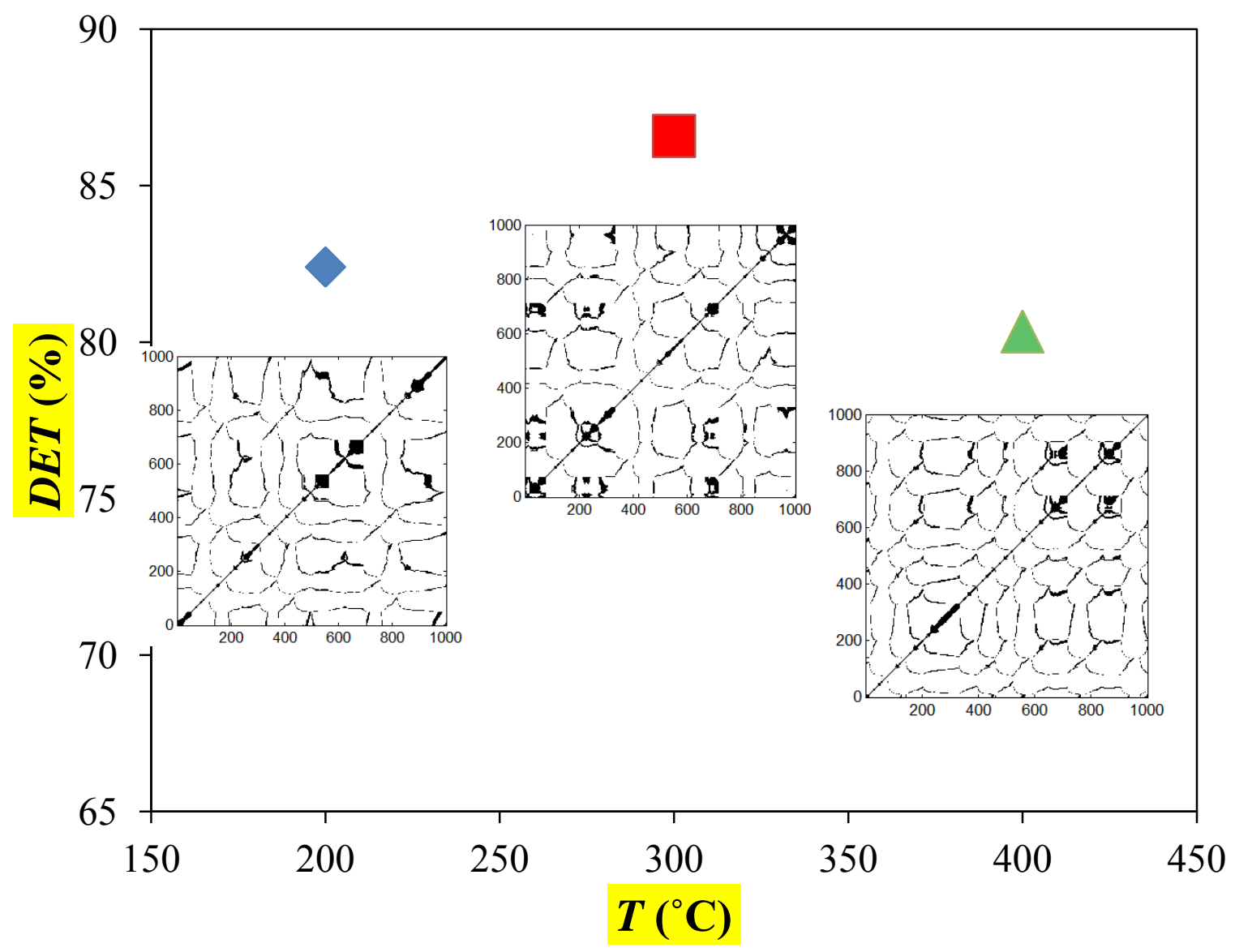

